Distribution

Category UC-403

SAND94-1743

Unlimitcd Rclease

Printed 1994

\title{
Geomechanics of Horizontally-Drilled, Stress-Sensitive, Naturally-Fractured Reservoirs
}

\author{
David J. Holcomb \\ Stephen R. Brown \\ John C. Lorenz \\ William A. Olsson \\ Lawrence W. Teufel \\ Norman R. Warpinski \\ Sandia National Laboratories \\ Albuquerque, New Mexico 87185
}

\begin{abstract}
Horizontal drilling is a viable approach for accessing hydrocarbons in many types of naturally-fractured reservoirs. Cost-effective improvements in the technology to drill, completc, and producc horizontal wclls in difficult gcologic environments require a better understanding of the mechanical and nuid-flow bchavior of these reservoirs with changes in effective stress during their devclopment and production history. In particular, improved understanding is needed for predicling boreholc stability and rescrvoir response during pore pressure drawdown. To address these problems, a cooperative project between Oryx Energy Company and Sandia National Laboratories
\end{abstract}

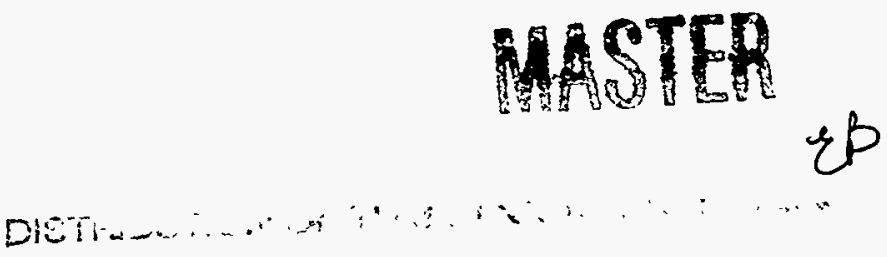


was undertaken to study the effects of rock propertics, in situ stress, and changes in effective stress on the deformation and permeability of stresssensitive, naturally-fractured reservoirs.

A low value for the poroelastic parameter was found, implying that the rescrvoir should have a low sensitivily to declining pore pressurc. A surprisingly diverse suite of fractures was identificd from corc. From the coring-induced fractures, it was plausible to conclude that the maximum principal stress was in the horizontal plane. Mcasurements on permeability of naturally fractured rock in a newly-developed experimental arrangement showed that slip on fractures is much morc effectivc in changing permcability than is normal stress. The intermediate principal stress was found to have a strong effect on the strength and ductility of the chalk, implying the necd for a more sophisticated calculation of borchole stability.

*This work performed at Sandia National Laboratories supported by the U.S. Department of Energy under contract number DE-AC04-94AL5000. 


\section{DISCLAIMER}

This report was prepared as an account of work sponsored by an agency of the United States Government. Neither the United States Government nor any agency thereof, nor any of their employees, make any warranty, express or implied, or assumes any legal liability or responsibility for the accuracy, completeness, or usefulness of any information, apparatus, product, or process disclosed, or represents that its use would not infringe privately owned rights. Reference herein to any specific commercial product, process, or service by trade name, trademark, manufacturer, or otherwise does not necessarily constitute or imply its endorsement, recommendation, or favoring by the United States Government or any agency thereof. The views and opinions of authors expressed herein do not necessarily state or reflect those of the United States Government or any agency thereof. 


\section{DISCLAIMER}

Portions of this document may be illegible in electronic image products. Images are produced from the best available original document. 


\section{Contents}

I Executive Summary 1

1 Introduction 1

2 Project Results 2

2.1 Characterization of Fractures in Horizontal Core From the Austin Chalk ................... 3

2.2 Effective Stress Law Behavior for Deformation and Fracture Conductivity ........................ 3

2.3 Hydromechanical Response of a Fracture Undergoing Compression and Shear . . . . . . . . . . . . . . . 4

2.4 Multiaxial Deformation and Failure of Austin Chalk . . . . . 5

2.5 Analysis of Reservoir Stress Path During Pore Pressure Drawdown 5

3 Results 5

4 Publications To Date From Project 6

II Task Reports 7

1 Characterization of Fractures in Horizontal Core From the Austin Chalk

2 Effective-Stress-Law Behavior for Deformation and Fracture Conductivity

3 Hydromechanical Response of a Fracture Undergoing Compression and Shear

4 Multiaxial Deformation and Failure of Austin Chalk 
(This page intentionally left blank) 


\section{Part I}

\section{Executive Summary}

\section{Introduction}

Horizontal drilling is a viable approach for accessing hydrocarbons in many types of naturally-fractured reservoirs. Cost-effective improvements in the technology to drill, complete, and produce horizontal wells in difficult geologic environments require a better understanding of the mechanical and fluid-flow behavior of these reservoirs with changes in effective stress during their development and production history. In particular, improved understanding is needed for predicting borehole stability and reservoir response during pore pressure drawdown. To address these problems, Oryx Energy Company and Sandia National Laboratories studied the effects of rock properties, in situ stress, and changes in effective stress on the deformation and permeability of stress-sensitive, naturally-fractured reservoirs. The project focused on a study of Austin chalk, which is a proven target for horizontal drilling.

Funding for the work was supplied by the Department of Energy's Oil Recovery Program, under the auspices of the Oil Recovery Technology Partnership. The Partnership was implemented by the Bartlesville Project office, under Thomas C. Wesson, Director. The work was facilitated by interactions with the staff at Oryx Energy Company including Ray Nelson, Steve Chitwood, Ed Robbs, Joe Perez, Howard J. White, Robert Skopec, and Harold A. Illich.

The objective of the project was to apply an integrated geomechanics approach to the problems and possibilities arising from the increasing use of horizontal drilling to access hydrocarbons in naturally-fractured reservoirs. In tight (low permeability) formations, vertical holes are inefficient for accessing the predominantly vertical fractures that are the main source of production. By comparison, horizontal holes have a higher probability of intersecting vertical fractures and can intersect many more fractures. However, producing vertical fractures tends to rapidly change the state of stress and thus influence the producibility of the fracture system. Because of the planarity of fractures, their aperture and hence permeability, are strongly effected by changing stress states.

To understand the interplay between production and producibility requires an understanding of how reservoir rock and fractures respond to changing pore pres- 
sures and the resultant changes in effective stress. By combining the capabilities of Oryx and Sandia, a comprehensive study could be made of the problems. Sandia has unique rock mechanics testing and computational facilities for studying fluid-flow and mechanical phenomena associated with fractured and unfractured hydrocarbon reservoirs. Examples of the successful application of Sandia's geomechanics expertise include (1) improvements in characterizing and stimulating tight gas sands through the MWX experiment and (2) showing the importance of drawdown-induced, effective-stress changes on reservoir deformation and permeability in the Ekofisk field. Oryx is a leader in horizontal drilling in the Austin chalk and is currently directing its efforts to other, more complex reservoirs. Their knowledge of the problems and phenomena of horizontal drilling, completions, and production of these reservoirs provided valuable input to this project.

An integrated study was proposed to increase understanding of the behavior of fractures in the Austin chalk. The study included determination of the morphology of the fractures and their response to stress and stress history. During production, the effective stress is dependent on the poroelastic response of the rock. An experimental program was included to determine $n_{\digamma}$, the poroelastic parameter for Austin chalk. Oryx records were searched in an attempt to obtain field data on effective stress as a function of pore pressure for correlation with the laboratory measurements. Finally, because the stresses encountered during drilling horizontal wells are more complex than for vertical wells, an experimental program was carried out to determine the failure surface for Austin chalk under general stress states.

\section{Project Results}

The goal was to study the Austin chalk reservoir using modern geomechanics techniques and ideas. From the viewpoint of geomechanics, a fractured reservoir can be viewed as a permeable, fractured matrix loaded by a 3 -dimensional effective stress that evolves with production. The question to be answered is: how does the producibility depend on the interaction between the fractured matrix and the evolving stress state? To address the question, aspects of the reservoir system that are stress-sensitive were chosen for study: i.e. intact material properties, reservoir stress path, poroelastic parameters of the intact and fractured material and characterization of the natural fractures by observational, experimental and theoretical techniques. 
Five tasks were identified:

1. Characterization of Fractures in Horizontal Core From the Austin Chalk

2. Effective Stress Law Behavior for Deformation and Fracture Conductivity

3. Hydromechanical Response of a Fracture Undergoing Compression and Shear

4. Multiaxial Deformation and Failure of Austin Chalk

5. Analysis of Reservoir Stress Path During Pore Pressure Drawdown

A summary of the work accomplished follows. For more details, each task is discussed individually in the later sections.

\subsection{Characterization of Fractures in Horizontal Core From the Austin Chalk}

An extensive study of the fractures found in core from a horizontal well in the Austin Chalk identified five fracture types, three of which are natural and two that are thought to be coring-induced. Considering the limited amount of core and the simple structural setting, this is a diverse array of fracture types. A class of unmineralized, planar natural fractures was identified that should be highly permeable in comparison to the older, mineralized natural fractures. A new class of coring-induced petal fractures was observed. Study of the morphology of the fractures led to the conclusion that the minimum in situ stress is parallel to the coring axis. This is the best orientation for drilling to intersect vertical fractures as it minimizes the stress tending to close the fracture. It was also deduced that the maximum principal stress appears to be in the horizontal plane and thus normal to the core axis.

\subsection{Effective Stress Law Behavior for Deformation and Fracture Conductivity}

As the reservoir is produced, the pore pressure decreases, increasing the effective stress (the stress supported by the reservoir rock). A material property, the poroelastic parameter $\alpha_{\epsilon}$, links the pore pressure $P$ and the effective stress $\sigma_{r f f}$ to the 
total stress $\sigma_{l u l, l}$ through the equation

$$
\sigma_{r f f}=\sigma_{t, i n l}-n_{r} l
$$

Because fracture closure is controlled by the effective stress, it was essential to measure $a_{r}$. It is common to assume either that $n_{r}$ is a constant, equal to 1 , or is given by

$$
n_{s}=1-\frac{\kappa}{\kappa_{s}}
$$

where $K^{\circ}$ and $k_{s}$ are the bulk moduli of the rock and grain material. From measurements it was found that $n$, varied from 0.35 to 0.45 compared to a value of 0.28 computed from the bulk moduli $k$ and $k_{s}$. Thus, the theoretical values are not a reliable estimate of $\alpha_{r}$. Similar measurements on other chalks of various porosities showed a correlation between chalk porosity and $n_{r}$. As porosity decreases, $\alpha$, also decreases. This is important because a lower value of $\alpha_{f}$ means that the effective stress will change less as the reservoir is produced, making the reservoir less sensitive to declining pore pressure.

\subsection{Hydromechanical Response of a Fracture Undergoing Com- pression and Shear}

Pore pressure declines due to production and abrupt changes in pressure during stimulation can subject fractures to both compression and shear. While studies of fracture permeability and mechanical properties are common for changing normal stress (compression), there is little experimental work on the effects of shearing. A newly-developed experimental technique (Olsson, 1992), combining rotary shear with radial flow, was used to study the effects of normal stress and shear offset on the permeability of natural fractures. Experimental results were successfully compared with computed results obtained using a micromechanical model capable of incorporating detailed information about fracture surfaces obtained from a scanning laser profilometer. The most surprising result was that for an initiallymated fracture, shear motions of 1-2 mm caused order of magnitude increases in permeability, as compared to decreases by a factor of 2-3 for the expected range of normal stresses. Thus large increases in permeability can be expected if the faces of a mated fracture move relative to one another as a result of changes in stress such as might occur during stimulation activities. 


\subsection{Multiaxial Deformation and Failure of Austin Chalk}

The stability of boreholes and the response of reservoirs to production-induced changes in effective stress are largely determined by the rock properties when subjected to general, three-dimensional stress fields. In the vicinity of a borehole the principal stresses are almost always unequal. This fact, plus the increased ability to control the orientation of horizontal boreholes relative to the in situ stress, were the motives for examining the effects of the intermediate principal stress on deformation and failure of Austin Chalk. Measurements of the failure surface show that there is a strong maximum in strength as the intermediate stress increases to about $90 \mathrm{MPa}$, followed by a decline in strength at higher values of $\sigma_{22}$. Ductility, as measured by strain at failure, decreased as the intermediate stress increased. The results imply that borehole stability calculations would be improved by using true triaxial test results instead of conventional triaxial tests.

\subsection{Analysis of Reservoir Stress Path During Pore Pressure Draw- down}

Almost no usable data were found concerning the in situ stress state and its evolution during production. It is not customary to record the data necessary for obtaining this important quantity. Therefore, changes in effective stress were estimated using the measured values of $a_{f}$ and assuming uniaxial strain boundary conditions. Because of the low value of $a_{c}$, the effective stress was relatively unchanged by decreasing pore pressure.

\section{Results}

Key insights were obtained concerning geomechanics issues associated with horizontal drilling in the Austin chalk. A low value for the poroelastic parameter was found, implying that the reservoir should have a low sensitivity to declining pore pressure. A surprisingly diverse suite of fractures was identified from core. From the coring-induced fractures, it was plausible to conclude that the maximum principal stress was in the horizontal plane. Using a newly-developed experimental arrangement, permeability measurements of naturally fractured rock showed that slip on fractures is much more effective in changing permeability than is normal stress. The intermediate principal stress was found to have a strong effect on the 
strength and ductility of the chalk, implying the need for a more sophisticated calculation of borehole stability.

\section{Publications To Date From Project}

1. Olsson, W. A., The effect of slip on the flow of fluid through a fracture. Geophys. Res. Lett., 19, 541-543, 1992.

2. Warpinski, N. R. and L. W. Teufel, Laboratory measurements of the effectivestress law of carbonate rocks under deformation, Int. J. Rock Mech. Min. Sci. \& Geomech. Abstr. 30, 1169-1172, 1993.

3. Olsson, W. A. and S. R. Brown, Hydromechanical Response of a Fracture Undergoing Compression and Shear, Int. J. Rock Mech. Min. Sci. \& Geomech. Abstr., 30, pp. 845-851, 1993.

4. Warpinski, N. R. and L. W. Teufel, Laboratory measurements of the effectivestress law of carbonate rocks under deformation, Sandia National Laboratories Report SAND 94-0012, 1994. 


\section{Part II Task Reports}




\title{
1 Characterization of Fractures in Horizontal Core From the Austin Chalk
}

\author{
John Lorenz
}

\section{Methods}

The principle data set for this study consisted of $102 \mathrm{ft}$ of near-horizontal core from Oryx's Burton O. George Jr. No. 1 well. This well was drilled into the Austin Chalk in the Pearsall oil field, Zavala County, Texas. This core is extensively fractured, containing several types of both natural and induced fractures. Additional observations were made on horizontal core from Oryx's Las Vegas Ranch No. 57 well, in Dimmit County, Texas, for comparison.

All fractures were carefully described in order to distinguish natural from induced fractures, to recognize different categories of each type, to allow inferences as to their origins, and to determine whether fracture distribution is related to the lithologic heterogeneity of the reservoir. Photographs were made of each fracture type, highlighting their characteristics. The capability of distinguishing fracture types is important since only natural fractures are important to in situ reservoir permeability, and certain types of the natural fractures allow more permeability than others. Although the induced fractures are not present within the reservoir and do not enhance permeability, they are important because their characteristics provide information on the in situ stress system, which in turn controls the permeability of the natural fractures.

Once fractures could be distinguished by type, a log of the fracture locations was constructed. With known fracture locations, fracture spacings could be noted and statistically analyzed for patterns. All fractures contribute to some degree to the overall porosity of the reservoir and are important to calculations of strain for the reservoir. However, smaller natural fractures add very little to the system permeability whereas a few larger, less mineralized fractures may dominate it. Moreover, closely spaced fractures provide essentially single permeability conduits, whereas isolated smaller fractures are insignificant in system permeability calculations.

Finally, the Formation Microscanner (FMS) log that was run in the Burton O. George well was analyzed. This $\log$ was run as a fracture identification tool, 
with the hope that it would provide an extended data base for this well, having been run over the cored interval and for several hundreds of feet above and below the interval. Unfortunately, the log was either not run properly or there were insurmountable logistical problems. Therefore, it was impossible to correlate fractures seen in core with "fractures" portrayed on the log, and the log could not be calibrated to the known fracture types or locations. No further study was made of this log.

\section{Results}

Core from the Burton $\mathrm{O}$. George well contains three types of natural fractures and two types of induced fractures. Core from the Las Vegas Ranch well contains induced fractures of types similar to those in the Burton O. George core, but contains only one natural fracture. Only the Burton $O$. George fractures were analyzed fully, and these are the fractures discussed below.

\section{Natural Fractures}

Eight large, calcite-mineralized "macrofractures" occur in this core. These fractures retain some visible intercrystalline porosity, and thus may provide a certain amount of formation permeability. This type of fracture may be related to the second type of natural fracture, the tightly mineralized, narrow, natural "microfractures", of which there were 62 noted in the core. Of this population of 62 , eight were broken open and presented obvious films of mineralization on the fracture faces, whereas the core around the other 54 remained intact. This second type of fracture is as tight as the matrix rock in terms of either porosity or permeability, and is insignificant to production from the reservoir.

The third type of natural fracture probably has the greatest significance to reservoir production characteristics. These fractures (of which 25 were noted in the Burton $\mathrm{O}$. George core and which include the single natural fracture found in the Las Vegas Ranch core) are unmineralized. The absence of mineralization implies that these were the most recent natural fractures to form. Except for subtle plumose surface ornamentation, these fractures are exceptionally planar.

Both planarity and lack of mineralization enhance permeability potential. Thus these are the fractures that should be tested in the laboratory for permeability, 
stress, and surface characteristics in order to understand the potential reservoir deliverability.

Natural fractures are present only in the limestone facies. None were observed within the interbedded calcareous shales, and in fact, several were observed to terminate at the contact with a shale. This implies a limited vertical permeability to the system; i.e., permeability may be continuous within the individual limestone beds that comprise the reservoir, but poor between beds separated by interbedded shales.

Fracture spacing was analyzed for the macrofractures and the microfractures. However, spacings of the planar fractures could not be analyzed because, since the core is separated across the unmineralized surfaces, pieces of the core were commonly removed, of uncertain orientation (upside-down?), or out of order. Thus exact locations of these fractures could not be determined. It is assumed that the spacing pattern of these fractures mirrors the pattern documented for the other two types of fractures.

For the other two types of fractures, however, spacings are irregular, ranging from less than one inch to over $17 \mathrm{ft}$ (Fig. 1). The measured spacings can be broken into two sub- populations, one of one foot or less between fractures that describes fracture swarms, and another of greater than one-foot spacing. It is of interest that the latter population comprises only $30 \%$ of the individual spacings yet covers over $75 \%$ of the core length, implying that the fractures tend to be concentrated in groups or swarms with relatively few isolated fractures being found.

\section{Induced Fractures}

Two types of fractures that were created by the coring process are present in the cores examined. The most distinct type of these artificial or "induced" fractures has a notable saddle-shaped morphology that resulted from the interaction of the in situ formation stresses with the superimposed bit stresses. Forty-nine examples of this type of fracture were noted in the Burton $\mathrm{O}$. George core. These fractures are interpreted to be a type of petal fracture unique to horizontal core. Their spacings are related to drilling techniques.

The surfaces of these fractures display distinct plumose patterns, commonly with an obvious point of origin and short- radius curvature (Fig. 2). The direction of curvature is most often that which changed the direction of fracture propagation to horizontal, implying that the horizontal maximum in situ compressive stress exceeded the vertical compressive stress. This observation has yet to be 
corroborated by other measurements, but neither has it been controverted. It has significant implications for reservoir development and production techniques if true.

The last category of fractures is one of induced fractures that have the distinct, high-relief/short-radius curvature surface plumose structure of the saddle fractures but that are more planar in overall shape. They are not as planar as the planar natural fractures, however. The origin of these fractures is nebulous, although they may be related to the saddle fractures. If so, the stress ratios were highly anisotropic and the bit stresses that caused fracturing were overwhelmed by the in situ stresses very near the face of the bit. Twenty-five of these fractures were recorded in the Burton O. George core. 


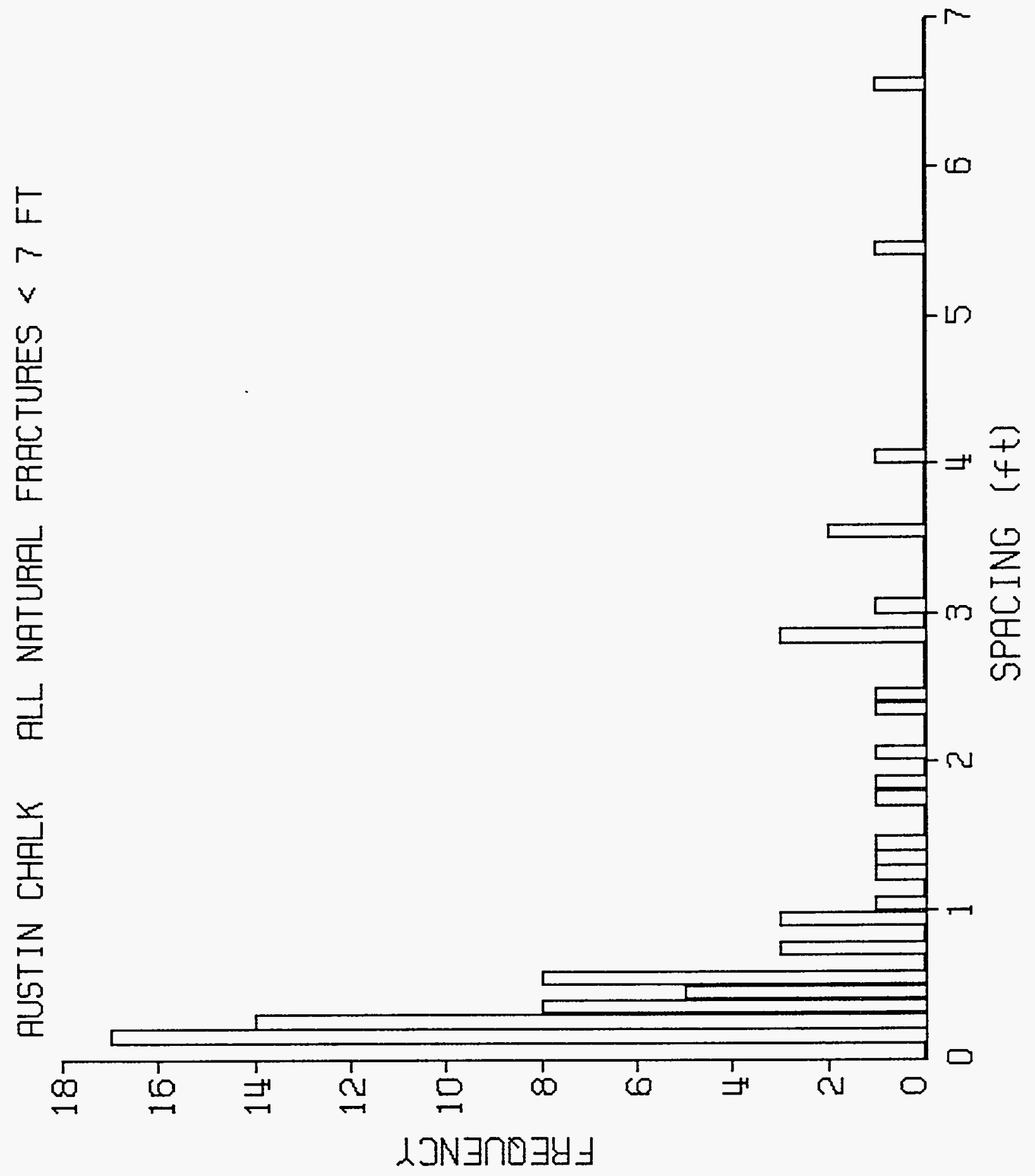

Figure 1. Spacing distribution for natural frạctures

0 


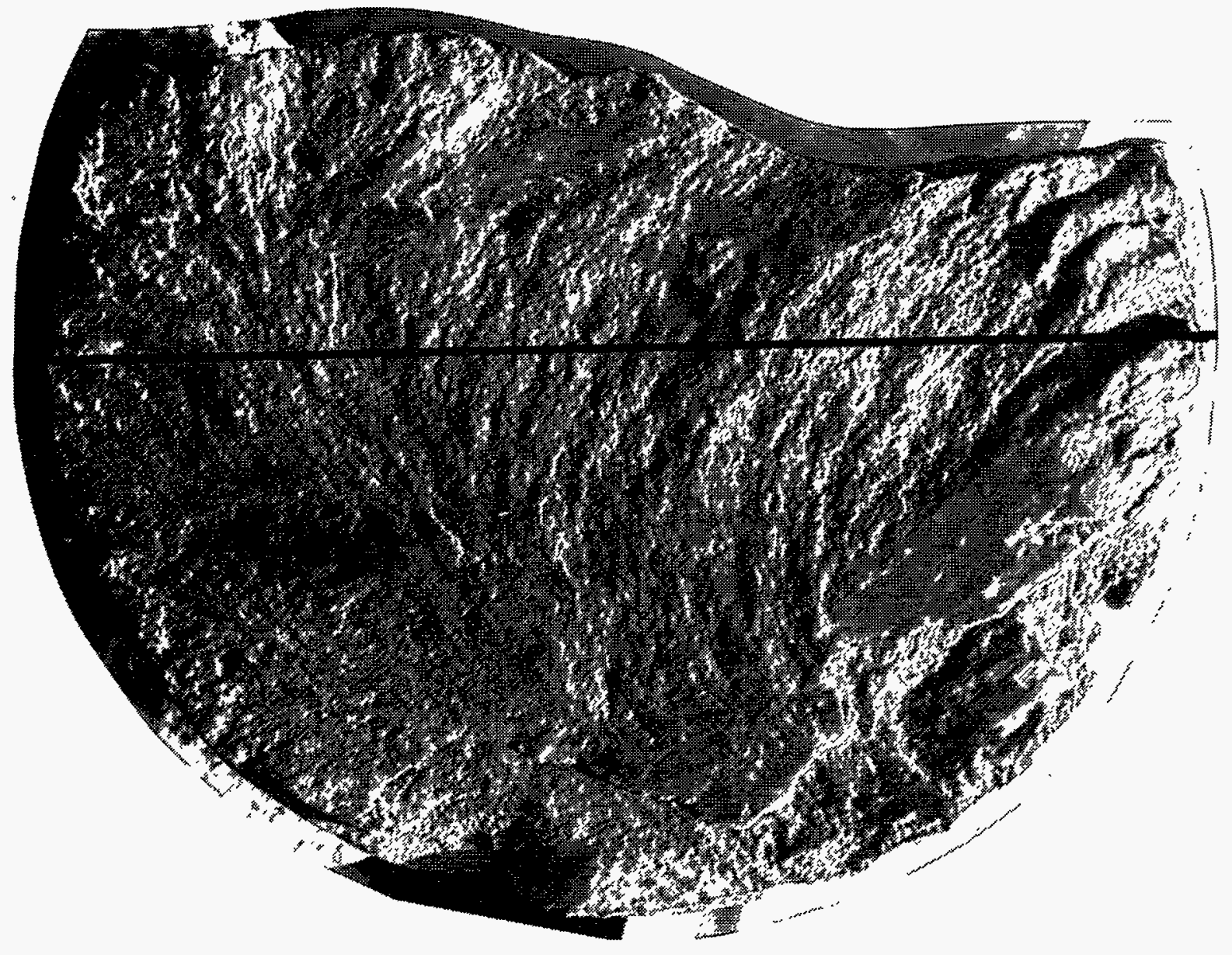

Figure 2. Coring-induced fracture, showing typical plumose patterns. 


\title{
2 Effective Stress Law Behavior for Deformation and Fracture Conductivity
}

\author{
Norman R. Warpinski and Lawrence W. Teufel
}

The focus of this part of the study is the effective stress law behavior of the reservoir, in terms of the deformation of the matrix and the conductivity of the natural fractures. Of particular importance is the understanding of the behavior of the matrix rock and the natural fractures with drawdown of the reservoir. Drawdown of the reservoir changes the effective stress, the total stress, and the deviatoric stress within the reservoir. The amount of change is strongly influenced by the effective stress law of deformation for the matrix material (the chalk). This type of behavior has never been studied for the chalk.

The changes in stress in turn affect the closure and, thus, conductivity of the natural fractures. To our knowledge, the stress sensitivity and conductivity effective stress law of fractures within the Austin chalk have not previously been tested.

During the course of this study, the deformation effective stress law behavior of two Austin chalk matrix samples were studied in great detail. Because of unexpected results for this low-porosity material, a higher porosity limestone, from the Saratoga formation, was also tested to determine its properties relative to the Austin chalk. In addition, three Austin chalk natural fractures were tested for their conductivity properties.

\section{Overview}

The behavior of rocks under the combined effects of confining stress and pore pressure is an important issue for any in situ petroleum process. For reservoir and near-wellbore behavior, the important issues are permeability, porosity, deformation, and failure. For reasons given below, only aspects of permeability and deformation are addressed in this study.

In order to simplify the difficulties in dealing with two independent parameters, it is customary to introduce an effective stress law which relates a net, or effective, stress to some combination of confining stress and pore pressure. This law is usually given as 


$$
\sigma_{\mathrm{eff}}=\sigma-\alpha p
$$

where $\sigma$ is the stress, $p$ is the pore pressure, and $\alpha$ is a parameter or function that may depend upon both stress and pressure. The classical effective stress law, given by

$$
\sigma_{\mathrm{cff}}=\sigma-p,
$$

is a simplification of equation 1 that is usually applied to soil mechanics and certain rock mechanic properties. For example, Robin ${ }^{1}$ shows theoretically that pore volume compressibility of normal reservoir rocks essentially follows the classical effective stress law, and Cornet and Fairhurst ${ }^{2}$ summarize empirical data showing that failure of rocks also follows the classical effective stress law. The remaining two important issues, permeability and deformation, have only been slightly studied.

The major difficulty with application of poro-elasticity or other uses of an effective stress law is obtaining an accurate model for the material behavior, as rocks are often heterogeneous, nonlinear and anisotropic. Furthermore, Robin ${ }^{1}$ has demonstrated that the effective stress law is dependent upon the particular property or process that is active (e.g., failure, deformation, permeability), so that different laws will be required for each. Deformation and fracture conductivity are, thus, treated separately.

\section{Experimental Procedure}

The experimental procedure ${ }^{3,4}$ for deformation consists of measuring the volumetricstrain response of a rock subjected to a compression composed of varying hydrostaticconfining-stress and pore-pressure levels. An 8-in long Austin-chalk core sample, which was provided by Oryx Energy Company from the Burton O. George No. 1 well (Zavala County) at a depth of $7093 \mathrm{ft}$, was plugged in three mutually perpendicular directions, labeled A, B and C. Plug B was oriented along the hole axis; the orientations of plugs $A$ and $C$ relative to the vertical are unkown, but they both are perpendicular to the hole axis. Core Labs measured a porosity of $3.8 \%$ and a grain density of $2.70 \mathrm{gm} / \mathrm{cc}$ at this depth.

The Saratoga limestone sample was provide by ORYX from the Sonat Minerals, Inc. No. 1 well (vertical) from Sabine Parish, Louisiana. The depth of 
the chosen sample was $2737 \mathrm{ft}$; Core Labs testing yielded porosity of about $11 \%$, grain density of about 2.71, and air permeability of 0.1-0.7 md. The sample is approximately $85-95 \%$ calcite, with about equal amounts of clay and quartz. A one-inch diameter horizontal plug was taken from the sample and instrumented with strain gages in axial and circumferential configurations.

All four samples were strain gaged, emplaced in neoprene jackets, and inserted in a modified overburden coreholder. The overburden coreholder uses hydraulic fluid to apply confining stress, while nitrogen supplies the pore pressure. Feedthroughs on one endcap allow for strain-gage wire to exit the coreholder.

Samples are loaded and unloaded several times ("seasoning") with hydrostatic confining stress alone until rock behavior is stabilized (i.e., repeatable results are achieved on successive cycles), and the effects of relaxation microcracks are diminished. The samples are then saturated with the test fluid and measurements are made at various stress and pore-pressure levels, with care taken to avoid hysteresis and equilibration effects. To minimize pore-pressure-equilibration times, data were taken at constant pore pressure through both loading and unloading cycles in the confining stress.

Sample A was tested first, but the jacket failed immediately, resulting in hydraulic fluid contamination. Sample B and C were then tested, with good results. Finally the Saratoga limestone sample was successfully tested.

The apparatus used for conductivity tests is the same one employed for deformation. It consists simply of an overburden coreholder (pressure vessel), output flowmeters, input, output and differential-pressure transducers, a high-pressure nitrogen source (up to $5000 \mathrm{psi}$ ), and a high-pressure hydraulic-fluid pump (up to $10,000 \mathrm{psi}$ ). In the first two samples, the test fluid was nitrogen, in order to avoid chemical and capillary pressure effects and to improve pressure equilibrium between the fracture and the matrix. In the last sample, the test fluid was $\mathrm{KCl}$ water; water was used in an attempt to avoid turbulence corrections. Permeability measurements were made using the steady-state technique, a necessity to insure fracture-matrix equilibration. Except during seasoning cycles, pore pressures of the nitrogen tests were kept above 500 psi so that Klinkenberg corrections would not be needed. Pressure drops across the natural fractures varied from 5-300 psi depending on the type of test.

Three different natural fractures were chosen for this study. These included a hairline, slightly mineralized fracture, and two smooth, poorly mated natural fractures. The samples were prepared by: 
1. breaking apart the hairline, partially mineralized fracture (the other two were already separated;

2. epoxying the fractures back together;

3. taking a plug along the strike of the fractures; and

4. dissolving the epoxy.

The sample was then inserted in an overburden core holder and tested with nitrogen or $\mathrm{KCl}$ water.

Plug samples were allowed to equilibrate at each stress/pressure condition and then permeability data were taken every 5 seconds over a 5 minute period. These results were examined for any long-term trends (e.g., still equilibrating) and tests were rerun if not stabilized. Data were averaged over the 5-minute test period.

Prior to testing, all of the samples were put through a "seasoning process" by cycling up to maximum stress and back to low stress several times. Plug permeability was measured during these cycles, and the fracture was considered "seasoned" when permeabilities were identical on several successive cycles. Had the samples not been seasoned, then no effective stress law correlations could have been made, as the natural fracture would be changing with each test.

As in the deformation measurements, tests were run at constant pore-pressure cycles, both through loading and unloading in order to minimize equilibration time and to avoid having pore-pressure-hysteresis effects embedded within stresshysteresis effects. Loading data were analyzed as one set and unloading data as a second, separate set.

\section{Analysis Procedure}

The analysis procedure ${ }^{3,4}$ for both deformation and conductivity uses a statistical technique whereby an empirical response surface of either volumetric strain or conductivity is mathematically generated. ${ }^{5}$ To do this, the volumetric strains or conductivities are (1) power-law transformed and (2) fit in a least-squares sense by a quadratic surface in both $\sigma$ and $p$. The resultant mathematical form of the response surface is given by

$$
\theta^{\lambda}=x_{1}+x_{2} \sigma+r_{3} p+r_{4} \sigma^{2}+x_{5} \sigma p+r_{6} p^{2}
$$


or

$$
K_{f}^{\prime}=x_{1}+r_{2} \sigma+x_{3} p+r_{4} \sigma^{2}+x_{5} \sigma \mu+x_{6} \mu^{2}
$$

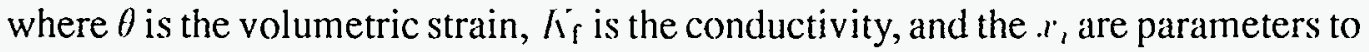
be fit. The power law $(\lambda)$ employed is determined through a maximum-likelihood approach. ${ }^{5}$ Given this empirical function, of the form $\theta(\sigma, p)$ or $K_{f}(\sigma . p)$, Bernabe's formula $a^{6}$ for the tangent can be employed as

$$
n=-\frac{\partial \theta}{\partial p} / \frac{\partial \theta}{\partial \sigma} \quad \text { or } \quad n=-\frac{\partial K_{f}}{\partial p} / \frac{\partial K_{f}}{\partial \sigma} \text {. }
$$

Additionally, standard statistical techniques can be used to determine confidence limits, regression coefficients, and other indicators of the quality of the fit and the variability of the data.

The attractive feature of this technique is that there is no a priori need to assume a model for the rock behavior, as is the case when a mechanistic model is fit to the data. This avoids any possibility of biasing the fit.

\section{Results and Discussion}

\section{A. Deformation}

An example of the deformation response curve is shown for sample B in Figure 1. Unloading refers to a decreasing confining stress at a constant pore pressure value. The lines on the surface are constant stress and constant pore pressure (the lines of constant pore pressure are the actual pore pressures at which data were taken). As can be seen in the figure, the data are well fit by the statistical surface, which is very flat. The value of a given on the figure $\left(a_{1}\right)$ is the value at low stress and low pore pressure (a first order approximation).

The equation of the statistical surface can then be manipulated to yield the value of $n$ at any point on the surface. Figure 2 shows the actual $\cap$ surface. The unloading $\Omega$ is about 0.46 at 500 psi confining stress and zero pore pressure, and about 0.39 at 8000 psi confining stress and 4000 psi pore pressure. The unloading $n$ shows an increasing value with increasing confining stress and a decreasing value with increasing pore pressure.

Similar testing was performed on sample $\mathrm{C}$ and on the Saratoga limestone sample. When all of these results are integrated with previous measurements 
of $\alpha$ in other carbonates, a general trend begins to emerge. Figure 3 shows the measured value of at a selected condition ( 5000 psi stress, 2000 psi pore pressure) as a function of porosity. The unloading data are presented here because they are considered to be the most accurate measure of $\alpha$. The value given by theory is also shown. The theoretical value ranges from about $15-30 \%$ lower than the measured value.

Figure 4 shows the measured and theoretical values of $\alpha$ as a function of permeability. Although this plot is a log scale, the measured data show a more consistent monotonic relationship between $\alpha$ and permeability than between $\alpha$ and porosity (Figure 3). This figure is only valid for one stress and pressure condition and there is some variability of $a$ with stress and pressure, but the results shown in Figures 3 and 4 are representative of the general behavior throughout the data domain studied in these experiments.

The results shown in Figures 3 and 4 illustrate that the theoretical value of $\alpha$ is not always a good approximation to the actual value. This discrepancy is not unexpected, as the theory requires that the skeletal material is homogeneous, that there is no unconnected porosity, that there are no inhomogeneities or discontinuities, and several other stipulations. In other words, the theory only holds for a perfect rock. For the Austin Chalk sample, $\mathrm{K}$ is about $6.8 \times 10^{6} \mathrm{psi}$ and $K_{\mathrm{s}}$ is about $9.1 \times 10^{6}$ psi. Thus, the theoretical value of $\alpha$ is about 0.25 , or about $25 \%$ less than measured.

The unloading data provide the best estimate of $\alpha$ because relaxation microcracks ${ }^{3}$ are least active in unloading. During loading conditions, relaxation microcracks that are already open require considerably greater pressures to reclose. In this study, the values of $\alpha$ in loading are slightly lower than the unloading values. This behavior suggests that the in situ value of $\alpha$ may be somewhat greater than these lab measurements show, as decreasing microcrack activity appears to increase $\alpha$. It is impossible to entirely eliminate the effects of relaxation microcracks in lab tests, but they can be minimized by seasoning the sample and using unloading data.

\section{B. Fracture Conductivity}

The first fracture tested, labeled fracture 1, was a hairline natural fracture with sparse mineralization on the surface of the fracture. This fracture was taken from the Burton O. George No. 1 core. The first set of tests run were seasoning cycles to try to stabilize rock behavior and provide reproducible rock conductivities on 
each successive run. The seasoning is usually performed by starting at some nominal confining stress (1000 psi) and pore pressure (500 psi), and increasing the confining stress in increments up to the maximum test value. Conductivity is measured at each increment through both loading and unloading cycles (back down to the original level). With most tight rocks, only one or two seasoning cycles are required. With this sample, $6000 \mathrm{psi}$ was chosen as a maximum confining stress value, but the rock behavior could not be stabilized. With each cycle the conductivity of the sample continued to decrease, and the loading was permanently damaging the sample.

The sample was taken out of the core holder and examined, and several areas exhibited crushed calcite residues. These were clearly the high points on the fracture and therefore experienced the greatest stress levels. These areas were thoroughly cleaned, the fracture was remated, and the sample was again inserted into the apparatus. This time the maximum confining-stress test value was 2000 psi, and the sample behavior was easily stabilized. These results clearly show that natural fractures in the Austin chalk are susceptible to permanent damage at relatively low stress levels.

A test matrix was then run on the sample to determine the effective stress law for fracture conductivity. The confining stresses were intentionally kept low to avoid any permanent damage to the fracture. The conductivity results are shown in the 3-D plot of Figure 5. While the conductivity is quite low, this fracture still has a permeability ranging from about 0.1 to $0.3 \mathrm{md}$, but the width is extremely narrow.

A plot of $n$ versus stress and pore pressure is shown in Figure 6. While this plot appears to show large variations in the behavior, the confidence limits on $\alpha$ are only about 0.3 at the $95 \%$ level. Thus, all that can be said about these results is that the value of a for this Austin Chalk fracture is near unity over the range tested. The poor confidence limits are due to two factors, the low conductivity of the fracture and the limited test range.

After completing the effective stress law matrix, the sample was reloaded several times in order to determine at what stress level permanent deformation begins. The first tests of this sample had used loading cycles up to 2000 and 6000 $\mathrm{psi}$, and the results were reversibility and permanent damage respectively. To better define the point at which damage begins to occur, loading cycles were run up to $3500 \mathrm{psi}$, and then $5000 \mathrm{psi}$. The $3500 \mathrm{psi}$ cycles possibly showed a small amount of continuing damage, but it was very small and difficult to consistently measure. The 5000 psi cycles showed a considerable amount of continuing, permanent 
damage. Since the pore pressure for these tests was $500 \mathrm{psi}$, this fracture will only sustain a net normal stress of about $2500-3000$ psi before it begins to irreversibly lose its conductivity.

Data from all three fractures were similar and they show that the conductivity is stress sensitive, but most of the sensitivity occurs within the first 1000 psi of loading. Natural fractures in the reservoir already have a higher loading on them, so additional stress effects, as would occur during drawdown, will not be large. Thus, production would not be likely to suffer much with moderate drawdown. However, with large drawdowns (so the net stress exceeds $3000 \mathrm{psi}$ ), the aspects of permanent damage become important and reservoir conductivity is likely to suffer irreversible declines. Under such conditions, remedial treatments, such as water fracs, are likely to clear out fines and provide better production until additional damage occurs.

\section{Conclusions}

We have completed an initial series of laboratory measurements of the deformation poroelastic response of Austin Chalk core. The sample tested was from the Burton $\mathrm{O}$. George \#1 well, at a measured depth of $7093 \mathrm{ft}$. The poroelastic parameter, $\alpha$, in the effective stress law,

$$
\sigma_{\text {eff }}=\sigma-a p,
$$

is found to have a value near 0.4 (at reservoir conditions) for deformation, much lower than any other rocks that we have tested. $\alpha$ is slightly dependent on stress and pressure.

These results have important implications for the mechanical behavior of the wellbore and the natural fractures. Since $\alpha$ is low, there is initially a very high effective stress within the reservoir. However, with drawdown, the effective stresses will not increase very much. Thus, wellbore stability will not change much with drawdown.

These results show that the value of $\Omega$ derived from equation 3 can be considerably in error. Measured values of $a$ are 0.1-0.2 greater than predicted for all samples tested, giving a $15-30 \%$ discrepancy.

For carbonates, there appears to be a trend of decreasing $\alpha$ with decreasing permeability and porosity. This is not unexpected since decreasing permeability and porosity indicate an increasing volume of grain material relative to pore space, which will increase $\mathrm{K}$. 
The experimental procedure and statistical analysis used here can provide accurate data on $\alpha$ for deformation of this rock. The $95 \%$ confidence limits on $\alpha$, based on the least-squares fit of the response surface for each sample, are \pm 0.03 for the Austin chalk, and \pm 0.06 for the Saratoga limestone over the range of experimental conditions.

Natural fractures in this rock show a factor of three reduction in conductivity with increasing stress up to a net stress of about 3000 psi. Above this value, permanent damage begins to occur and irreversible damage significantly decreases fracture flow characteristics.

It was not possible to obtain an accurate measurement of the effective stress law behavior of Austin chalk fractures, although some data suggest that $\alpha$ is not far from unity.

\section{References}

1. Corbett, K., M. Friedman and J. Spang, Fracture Development and Mechanical Stratigraphy of Austin Chalk, Texas. AAPG Bull., 71, pp. 17-28, 1987

2. Robin, P-Y. F., Note on effective pressure, J. Geophys. Res., Vol. 78, pp. 2434-2437, 1973.

3. Cornet, F.H. and Fairhurst, C., Influence of Pore Pressure on the Deformation Behavior of Saturated Rocks, Proc., Third Congress of the Int. Soc. for Rock. Mech., Vol. 1, Part B, pp. 638-644, Nat. Acad. of Sci., Washington, D.C., 1974.

4. Warpinski, , N.R. and Teufel, L.W., Determination of the effective-stress law for permeability and deformation in low-permeability rocks, SPE Formation Evaluation, Vol. 7, pp. 123-131, 1992.

5. Teufel, L.W. and Warpinski, N.R., Laboratory determination of effective-stress laws for deformation and permeability of chalk, Third North Sea Chalk Symp., Copenhagen, Denmark, 1990.

6. Box, G.E.P. and Draper, N.R., Empirical Model Building and Response Surfaces, John Wiley \& Sons, N.Y., 1987

7. Bernabe, Y., The effective pressure law for permeability in Chelmsford granite and Barre granite, Int.J. Rock Mech., Min. Sci.\& Geomech abstr., Vol. 23, pp. 267-275, 1986. 


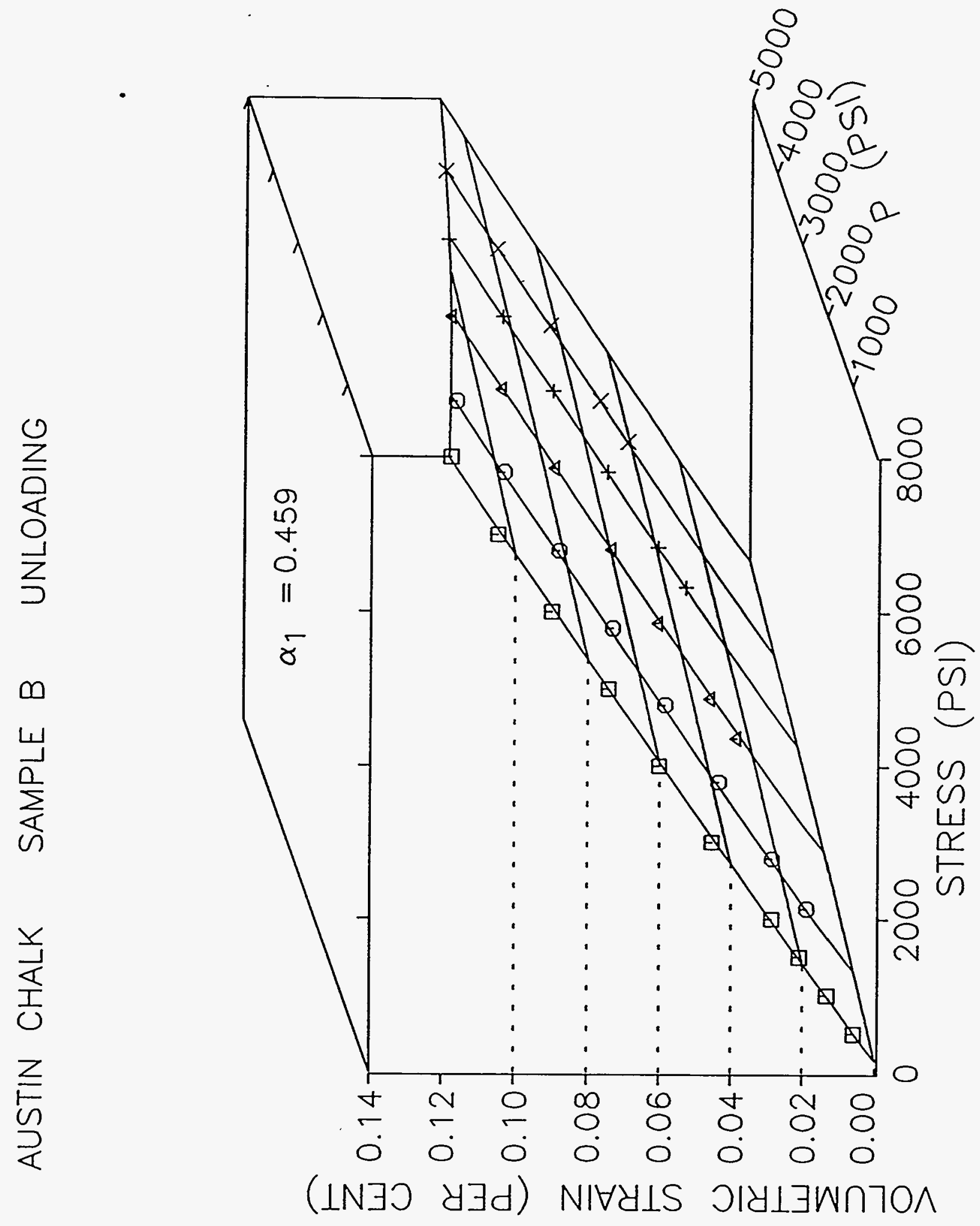

Figure 1 Volumetric strain response for sample B, unloading 

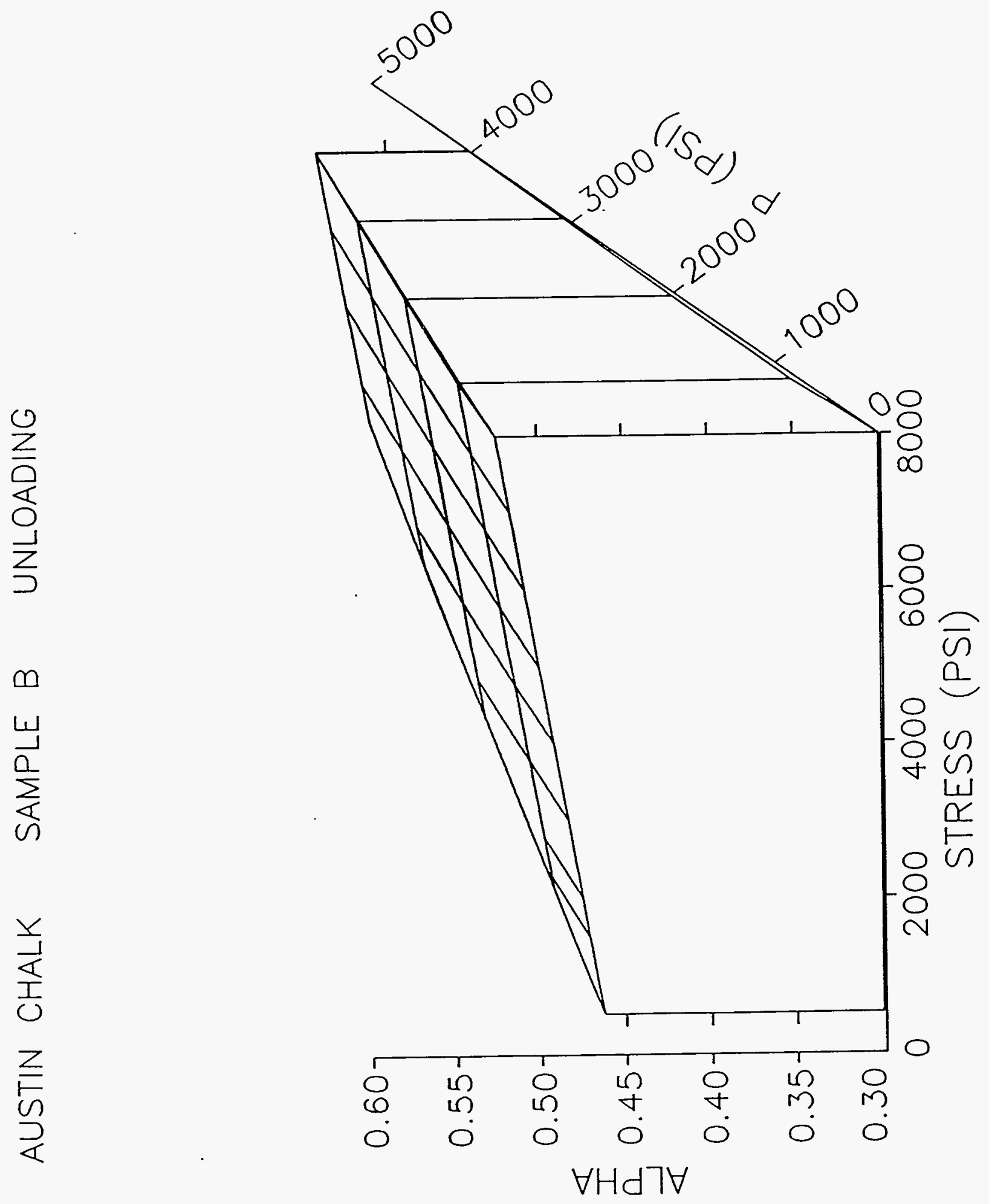

Figure 2. Alpha response for sample B, unloading 


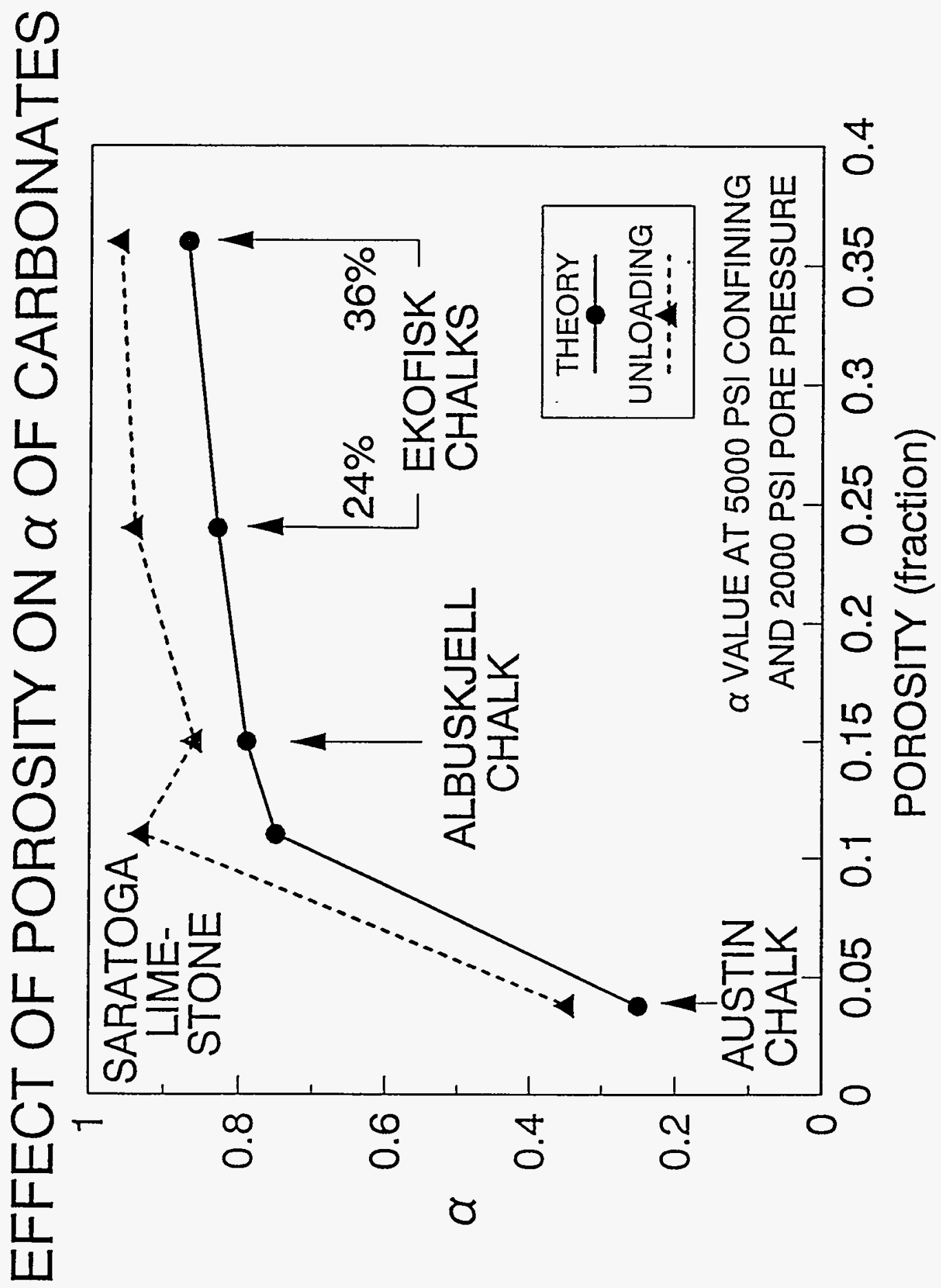

Figure 3. Alpha as a function of porosity 


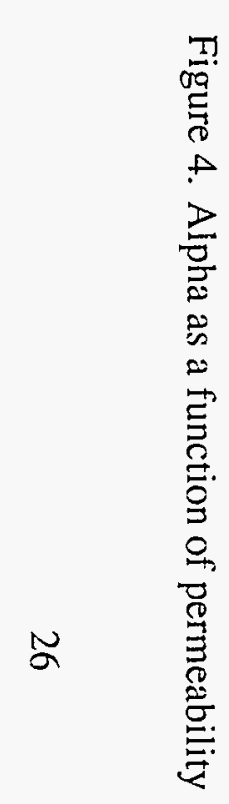

\section{EFFECT OF PERMEABILITY ON $\alpha$ OF CARBONATES}

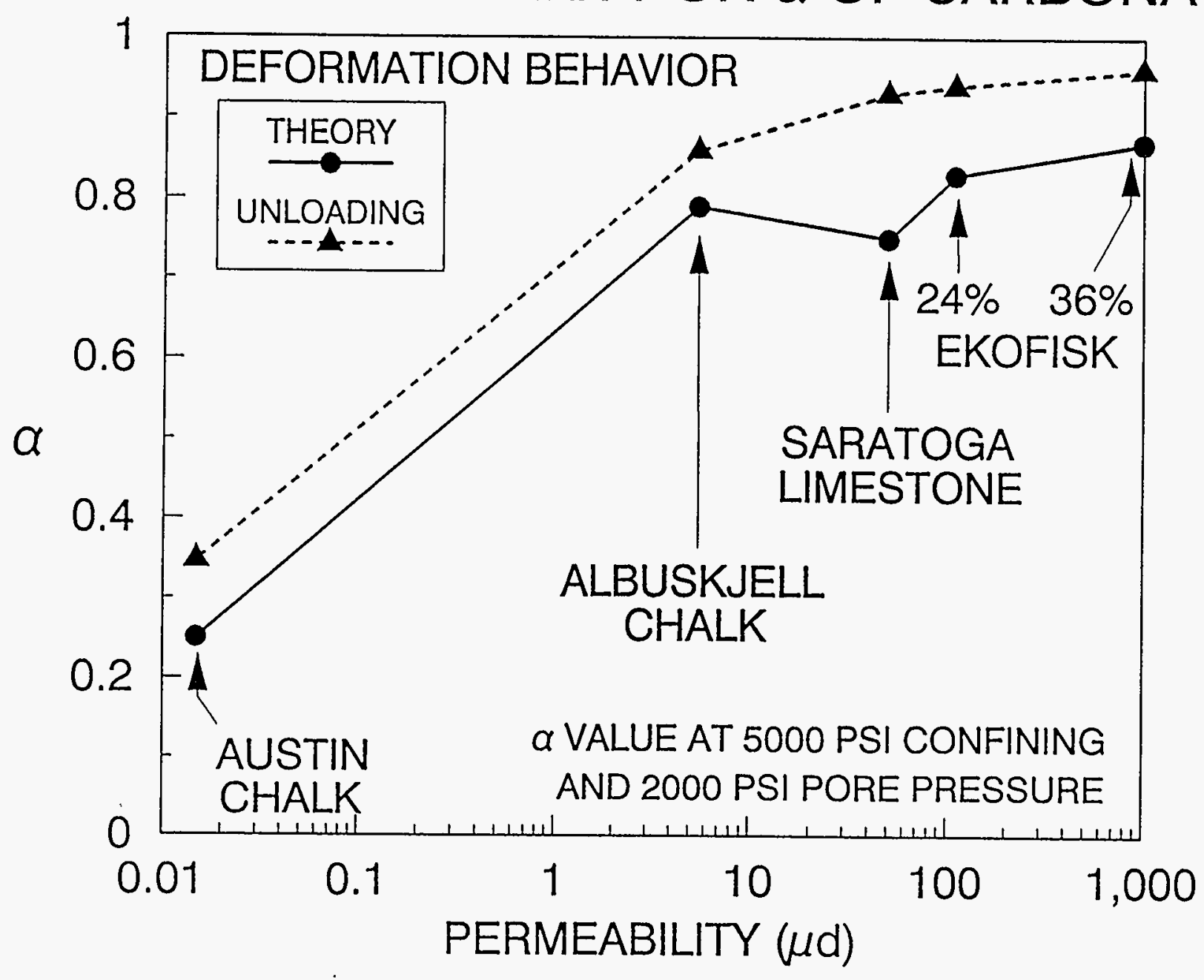




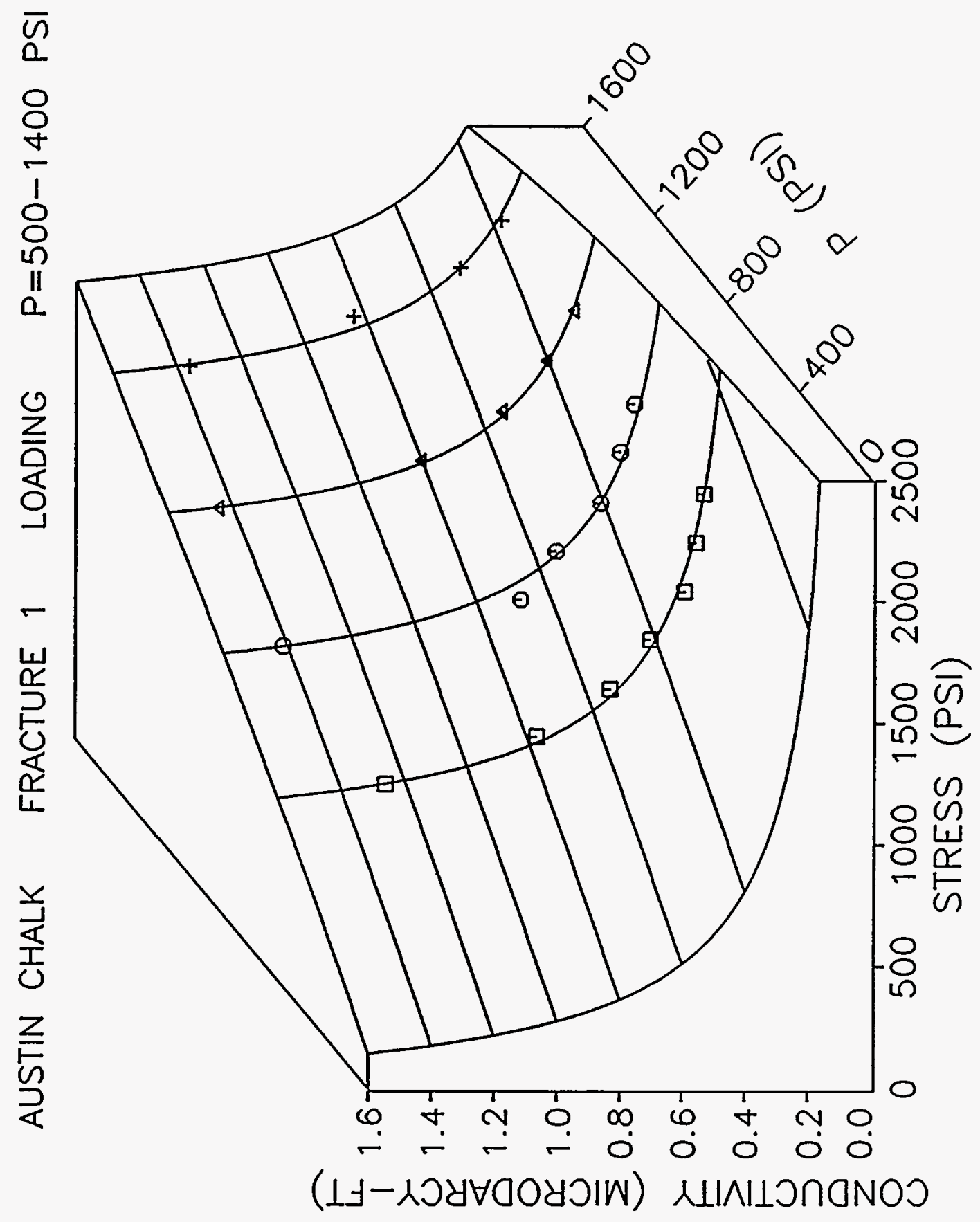

Figure 5. Conductivity response for fracture 1 


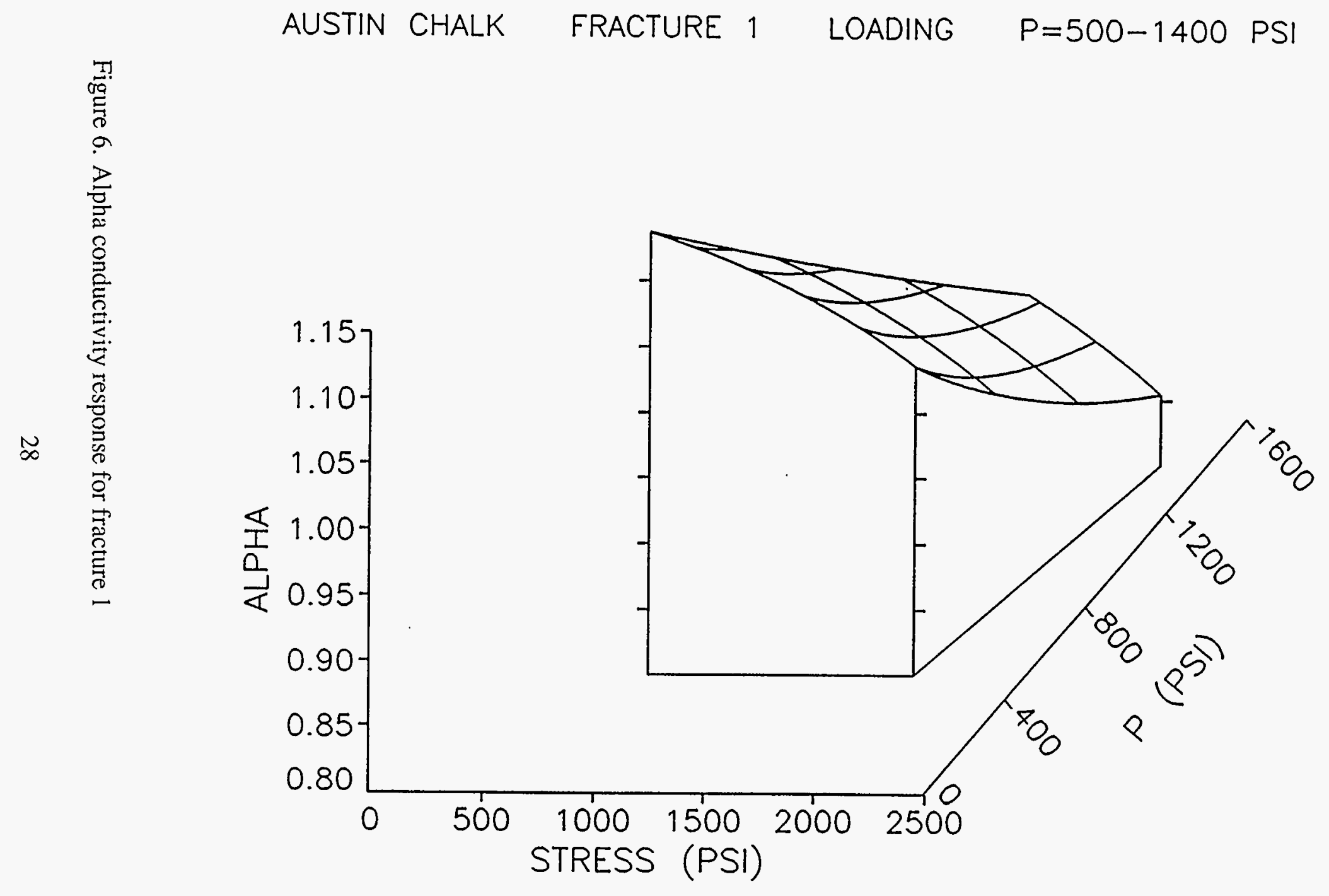




\title{
3 Hydromechanical Response Of a Fracture Under- going Compression And Shear*
}

\author{
William A. Olsson and Stephen. R. Brown
}

\section{Introduction}

Coupled fluid flow-rock deformation processes can be important in several geotechnical and natural phenomena. Water may flow through rock joints or faults into mined openings or around dams, stress sensitive fractures may affect hydrocarbon reservoir management, or radionuclides may migrate away from underground nuclear waste repositories along joints.

The effect of normal stress and closure on fracture flow rates has been much studied [1]. The effect of slip on fracture flow has been estimated theoretically but there has been little experimental work done on this effect [2].

Olsson [2] combined the rotary shear test with the radial flow geometry to study the effect of joint shear on fracture flow rates for a sawed and ground surface in tuff. In this study, we extend this work to the study of a natural fracture from drill core. We evaluate the effects of normal stress and shear offset on fluid flow rates with predictions from a microscopic theory of surface contact constrained by surface roughness measurements.

\section{Experimental Procedures}

The natural fracture used in this investigation was found in a core taken from an oil well drilled in Austin Chalk. The fracture surfaces were clean and undamaged, and without apparent mineralization. Sample halves could be closely mated, or interlocked, by hand. A short core was taken perpendicular to the fracture and used to construct a sample for the rotary shear test (Figure 1). When the two halves of the fracture were pressed together, the area of contact was washer-shaped with outside diameter of $60.3 \mathrm{~mm}$ and inside diameter of $24.0 \mathrm{~mm}$. An $8 \mathrm{~mm}$ diameter access hole was bored into the central cavity to allow the introduction of fluid.

A servo-controlled axial/torsion load frame was used to test the mechanical and fluid flow properties as a function of normal load, shear slip, and shear offset. The term "offset" denotes change in relative position effected during periods of

*This is an extended abstract of a paper of the same title submitted to the 34th Rock Mechanics Symposium, Madison, Wisconsin, 1993. 


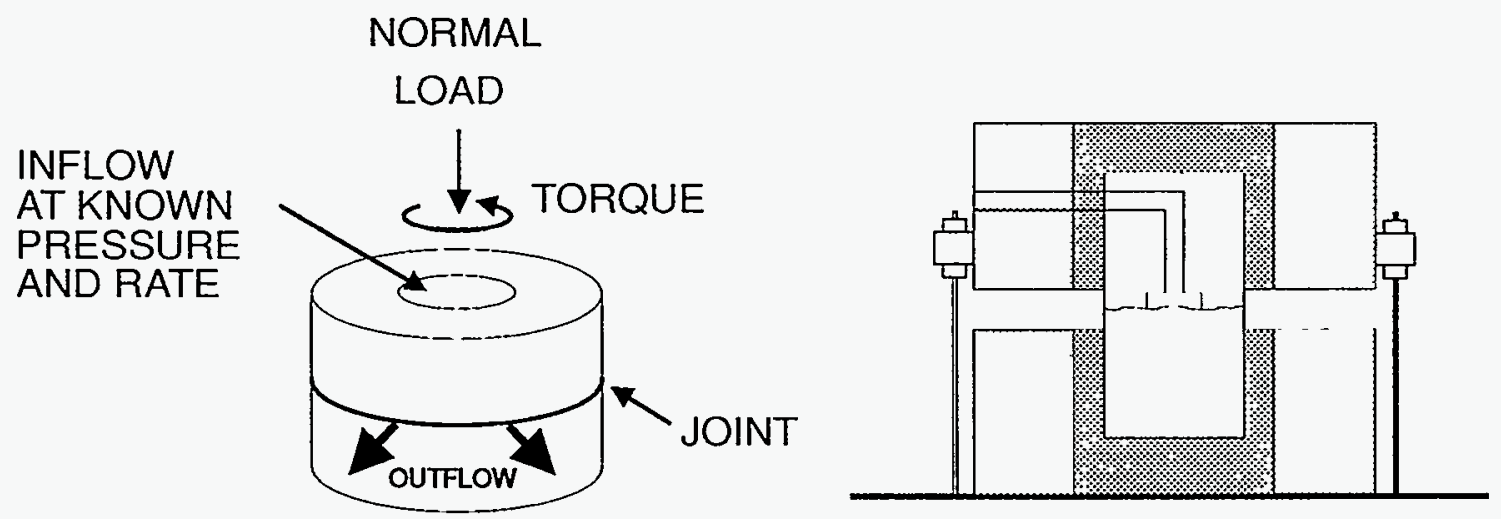

Figure 1: Sketch of rotary shear sample combined with radial flow test on left, and a cross-section of the experimental set up on right. The white area is the sample, the light gray is the aluminum holder, and the dark gray is the plaster of paris potting material. The LVDT mounting arrangement, inlet hole and internal cavity are also indicated. Sketch not to scale.

separation, and "slip" denotes change in relative position effected during periods of contact at non-zero normal stress.

The overall test sequence involved: (1) repeated normal compression loadings to $8 \mathrm{MPa}$ at each of $0,1,3 \mathrm{~mm}$ of shear offset. During these experiments fluid flow measurements were made at selected normal stress levels. (2) A shear sliding test at a constant normal stress of $4.3 \mathrm{MPa}$, where slip ranged from $0-3.5 \mathrm{~mm}$ from the perfectly mated condition. Dilation was recorded continuously, and flow measurements made at selected amounts of slip. (3) For $0 \mathrm{~mm}$ offset a normal compression/fluid flow test was done to $20 \mathrm{MPa}$ normal stress.

During all tests, steady-state fluid flow measurements were made at selected stress or slip levels with silicone oil. The fluid was moved at constant pressure by a sliding-piston dilatometer.

Prior to any experiments, the topography of the fracture surfaces was measured with a non-contacting laser profilometer. The sample was mounted in the profilometer in such a way as to allow matched pairs of profiles from each surface to be closely refitted in the subsequent analysis.

\section{Experimental Observations}

Compression cycles were applied when the surfaces were closely matched and after the fracture had been separated and offset to $1 \mathrm{~mm}$ and $3 \mathrm{~mm}$, respectively. The compression curve at $0 \mathrm{~mm}$ offset suggests that the fracture comes very near to closing at normal stresses of 8-20 MPa. The effect of offsetting the fracture 


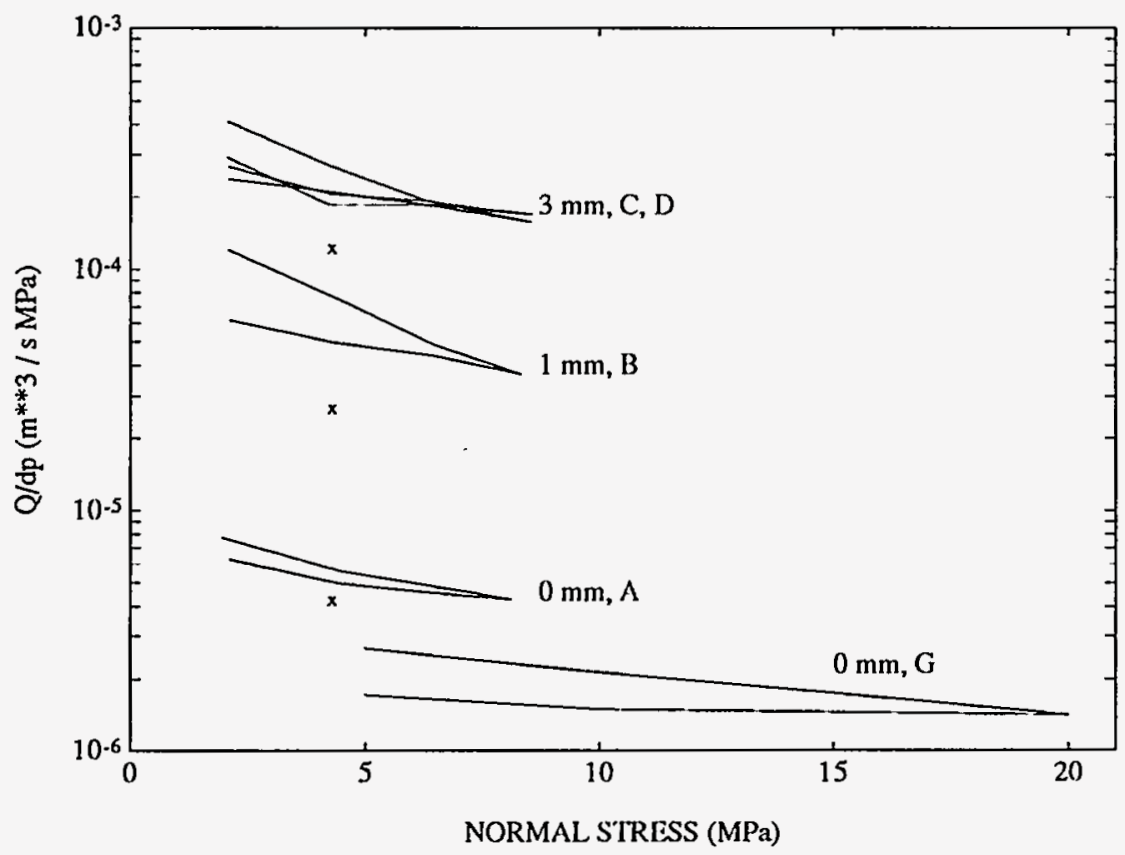

Figure 2: The solid lines show the effect of normal stress on flow rates at different amounts of offset. The fracture was offset while out of contact. The $x$ 's indicate the flow rates measured during shear at $4.3 \mathrm{MPa}$ normal stress at the equivalent offsets.

walls is to progressively decrease the normal stiffness of the fracture $K_{n n}$ as defined by $K_{n n}=d \sigma / d \delta$, where $\sigma$ is the normal stress and $\delta$ is the fracture closure. Increasing the offset from 0 to $1 \mathrm{~mm}$ causes a much larger change in the response than increasing offset from 1 to $3 \mathrm{~mm}$. At any given stress, the stiffness falls rapidly with increasing offset. Second compression cycles yielded higher stiffnesses than the first cycles.

The effect of normal stress and amount of offset on flow rates are shown by the solid lines in Figure 2. Increasing normal stress causes the flow rate to decrease and there is hysteresis in the response. The most striking aspect of the plot is that tangential movements of the fracture walls cause order-of-magnitude changes in fluid flow, whereas only factors of 2 or 3 occur due to change in normal stress of the magnitudes applied here.

The effect of sliding at constant normal stress on the flow rate was also measured. The sample halves were mated and a normal stress of of $4.3 \mathrm{MPa}$ was applied. The fracture was then slid to about $3.5 \mathrm{~mm}$. After reaching peak shear stress at about $0.2 \mathrm{~mm}$, the shear stress descends gradually with increasing slip 
to about $2 \mathrm{~mm}$ where the stress becomes approximately constant. The fracture opens steadily with increasing slip after peak stress. In a similar way, the flow rate changes little until peak stress, at which time it begins a steady increase with increasing aperture past peak stress.

At the termination of the shear test, the surface had several obvious damaged areas resembling slickensides in that the patches were shiny and appeared to represent areas of plastic deformation.

\section{Analysis}

We considered the role of surface roughness in determining the normal stress and shear offset dependent properties measured in the laboratory. A microscopic model of contact of rough surfaces based on the studies of Hertz has been shown to successfully describe the elastic properties of a single fracture including both normal and shear stiffness [3,4, for example|. In this model a fracture is composed of two contacting rough surfaces. This model shows that the mechanical properties are largely determined by the "composite topography" (negative of the aperture distribution) of the fracture. The surface topography parameters appearing in the model are things such as the number of contacts per unit area, the standard deviation of asperity heights, the probability density function for asperity heights, and the mean radius of curvature of the contacting asperities.

We used this model to analyze the three major normal stress and shear offset dependent properties of single fractures observed in the experiments.

1. Dependence of Normal Stiffness on Shear Offset. The matched profiles taken from the fracture were offset in shear from one another by 0,1 , and $3 \mathrm{~mm}$. At each offset the composite topography was computed and analyzed. Predictions of the changes in normal stiffness with shear offset from this microscopic model generally agree with the changes measured in the laboratory. The predicted stiffness at zero offset was"almost twice that observed. This error diminished with increasing offset.

2. Dependence of Fluid Permeability on Normal Stress and Shear Offset. The closure as a function of normal stress $\delta(\sigma)$ predicted by the theory is simply the change in aperture. Estimating the initial aperture $d_{0}$ from the surface profiles, we then have the aperture at any normal stress given by $d(\sigma)=$ $d_{0}-\delta(\sigma)$. To a first approximation the volumetric fluid flow rate through a fracture $Q$ depends on the aperture $d$ through the cubic law, where $Q \propto d^{\beta}$. Substituting $d(\sigma)$ in this relation gives the volumetric flow rate as a function of normal stress.

Using this stress-dependent aperture at each of the three shear offsets $(0,1,3$ $\mathrm{mm}$ ), the cubic law was used to calculate the fluid flow rate over a range of 
normal stresses. In all cases, the normal stress and shear offset dependence of the fluid flow rate can be fit reasonably well by the simple elastic model and the cubic law. The theory predicted a hydraulic aperture at zero offset of roughly twice that observed in the experiments. Again, this error diminished with increasing offset.

3. Dependence of Normal Dilation on Shear Offset. The experiments show that approximately the first $0.2 \mathrm{~mm}$ slip results in zero dilation. Also, it is over this same slip distance that the peak in the shear stress curve develops completely. Since the dilation and shear stress result from the interaction of two rough surfaces riding over one another, we suggest that there is an underlying geometric feature of the surface roughness controlling this behavior.

Fourier analysis of the surface profiles shows that the two fracture surfaces are closely matched with one another at wavelengths smaller than 0.2-0.4 $\mathrm{mm}$. This corresponds directly to the characteristic slip distance observed in the shear test. The intrinsic mismatch length defined in this way describes the sloppiness in the fit of the two surfaces. Apparently the surfaces can slide over this distance before the larger scale asperities interact enough to cause dilation.

\section{Summary}

This work demonstrates that in any engineering activity wherein shear stress is sufficient to cause slip on discrete fractures one can expect significant changes in the fluid permeability. For example, during water injection or hydrofracturing in an oil reservoir to enhance production, the effective normal stress on existing fractures may decrease enough to cause frictional sliding. If the fracture surfaces are initially well matched, then there may be a significant and permanent permeability increase associated with the fluid injection. If, however, the surfaces are initially poorly matched or misaligned then the opposite effect may be observed [2].

\section{References}

1. Cook N. G. W. Natural joints in rock: mechanical, hydraulic and seismic behavior and properties under normal stress. Int. J. Rock Mech. Min. Sci. \& Geomech. Abstr. 29, 198-223 (1992).

2. Olsson W. A. The effect of slip on the flow of fluid through a fracture. Geophys. Res. Lett. 19, 541-543 (1992). 
3. Brown S. R. and Scholz C. H. Closure of rock joints. J. Geophys. Res. 91, 4939-4948 (1986).

4. Yoshioka, N. and Scholz, C. H., Elastic properties of contacting surfaces under normal and shear loads 2 . Comparison of theory with experiment. J. Geophys. Res. 94, 17691-17700 (1989). 


\title{
4 Multiaxial Deformation and Failure of Austin Chalk
}

\author{
David J. Holcomb
}

\section{Background}

Mechanical properties of overburden and reservoir rocks affect the drilling, completion and production of wells. As wells are attempted in increasingly-difficult environments there is a need for a more complete understanding of the mechanical behavior of rock under in situ conditions. In particular, the stability of the borehole and the response of the reservoir to drawdown-induced effective stress changes are largely determined by the rock properties when subjected to multiaxial in situ stresses. Corbett et al. have reported on the mechanical properties of Austin chalk under standard triaxial conditions [1]. However, predicting failure and other non-linearities for multiaxial stress states requires development of a constitutive model incorporating the intermediate principal stress. A study was undertaken to determine the properties of intact Austin chalk under true triaxial stress in order to evaluate the complete failure envelope and quantify the importance of the intermediate principal stress on strength and ductility.

The effects of the intermediate principal stress are at least two-fold: strength increases as the intermediate principal stress increases and ductility decreases ([2], [3], [4], [5]). Increasing strength and decreasing ductility are opposing trends in terms of borehole stability. With the extra degree of freedom allowed by the ability to choose the orientation of a deviated hole, it should be possible to exert significant control over the intermediate principal stress and thus improve the borehole stability. Two recent papers indicate the importance of incorporating these effects. A failure criterion used by Ong and Roegiers ([6] is an example of the need for data on the effect of the intermediate stress on strength. Evaluation of the parameters requires true triaxial tests of the type undertaken in this work. Ductility was shown to be an important consideration in well bore stability in the work by Ewy et al. [7]. They found that by incorporating the ductility of the rock around the borehole into a finite element model, a more realistic estimate of the failure conditions could be made. 


\section{Experiments}

Austin chalk from a depth of about 7000 feet was tested. Except for two extension tests, all samples were tested with the maximum compressive stress perpendicular to bedding, Three types of experiments were done: conventional triaxial $\left(\sigma_{11}>\right.$ $\sigma_{22}=\sigma_{33}=P^{\prime}(\cdot)$, extensional $\left(\sigma_{11}=\sigma_{22}>\sigma_{33}=I^{\prime} \cdot(\cdot)\right.$, and true triaxial $\left(\sigma_{11}>\right.$ $\left.\sigma_{22}>\sigma_{33}\right)$. The conventional triaxial and extensional experiments were carried out in a standard servo-controlled load frame and pressure vessel. Test specimens were 1 inch diameter cylinders, approximately 2.25 inches long. To apply extensional stress, an O-ring face seal was used on the end caps to prevent the confining pressure fluid from reaching the ends of the sample. As long as the load along the axis of the sample was greater than the force exerted on the loading piston by $\sigma_{33}$, the fluid pressure, the stress in the axial direction could be controlled. Tests were done in a pressure vessel with a 4 kilobar capacity. True triaxial tests were accomplished using a load frame designed by Wawersik and Carlson ([8]). Samples were parallelepipeds of Austin chalk 2.25 inches by 2.25 inches by 1 inch. Fluid pressure applied to the large face supplied the minimum compressive stress. Miniature hydraulic jacks, using the vessel wall as a reaction frame, produced the intermediate principal stress. The main loading ram was used to apply the maximum compressive stress. All three strains could be measured by various gages. Tests were carried out at strain rates of about $5 \times 10^{-5} \cdot s^{-1}$ under servo control.

Results can be ordered by the magnitude of the intermediate stress relative to the maximum and minimum compressive stress. For conventional triaxial tests, the intermediate stress is equal to the minimum compressive stress. For true triaxial tests, the intermediate principal stress is indeed intermediate between the maximum and minimum. Extensional tests are conducted with the intermediate stress equal to the maximum compressive stress.

\section{Conventional Triaxial Tests}

Four conventional triaxial tests were conducted at conditions listed in Table 1. Strength $\left(\sigma_{11, \text { mas }}\right)$ as a function of confining pressure was found to increase approximately linearly (see Figure 1). A least squares fit to the data resulted in

$$
\sigma_{11 \text { max }}=41,200 \mathrm{psi}+2.98 \sigma_{33} \text {. }
$$


Using the Coulomb criterion for failure, this corresponds to a cohesion $S_{0}=$ $11,900 \mathrm{psi}$ and a coefficient of internal friction $\mu=0.57$. Figure 2 shows the results in the Mohr circle representation.

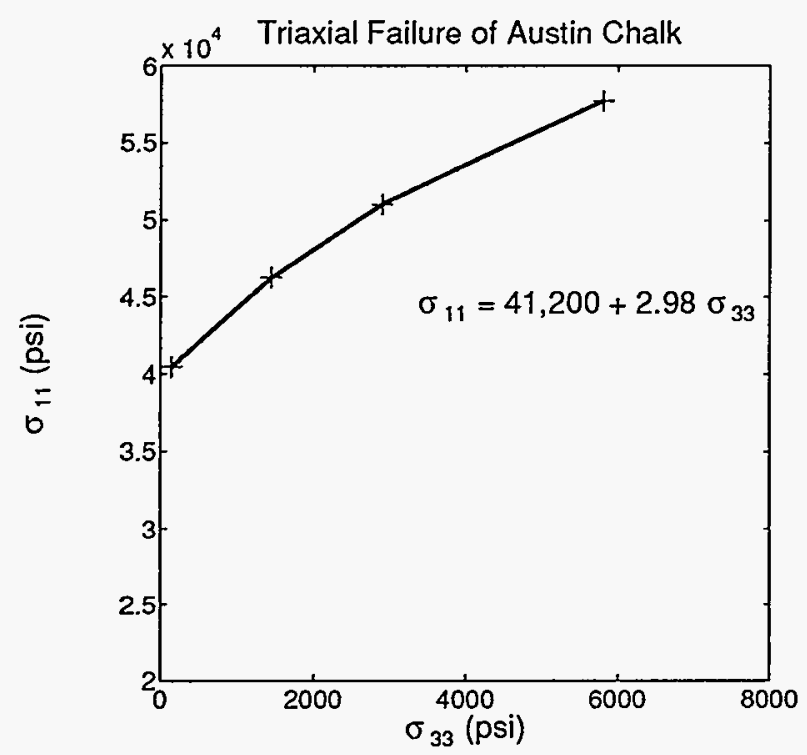

Figure 1: Strength of Austin chalk, plotted in the conventional triaxial plane

Ductility is a function of confining pressure, as Figure 3 shows. At $P_{c}=145$ psi, the chalk was nearly linear elastic up to failure. As $P_{\mathrm{r}}$ increased, the amount of strain in excess of what would be predicted from the initial elastic response increases. Table 1 shows the excess strain $\epsilon_{33 \text {,max }}^{\prime}$ in the direction of the minimum compressive stress $\sigma_{33}$. Excess strain, or plastic strain, was computed by fitting the early part of stress-strain curve with a linear fit, predicting the expected strain at the maximum stress and subtracting the prediction from the observed strain. A larger value for $\epsilon_{33, \text { ma. }}^{\prime}$ indicates greater ductility.

Young's modulus $(E)$ and Poisson's ratio $(\nu)$ were determined by a linear fit to the low-stress portion of the data. From Table 1, there is no apparent dependence of $E$ and $\nu$ on $\sigma_{33}$. Within the accuracy of the data, Young's modulus was approximately constant and equal to $8.8 \times 10^{6} \mathrm{psi}(61 \mathrm{GPa})$ and Poisson's ratio was 0.3. By comparison, Martin et al. ([9]) found Young's modulus and Poisson's ratio to be $4.4 \times 10^{6} \mathrm{psi}(30 \mathrm{GPa})$ and 0.23 for chalk from the same well and depth. No reason is known for the discrepancy. 


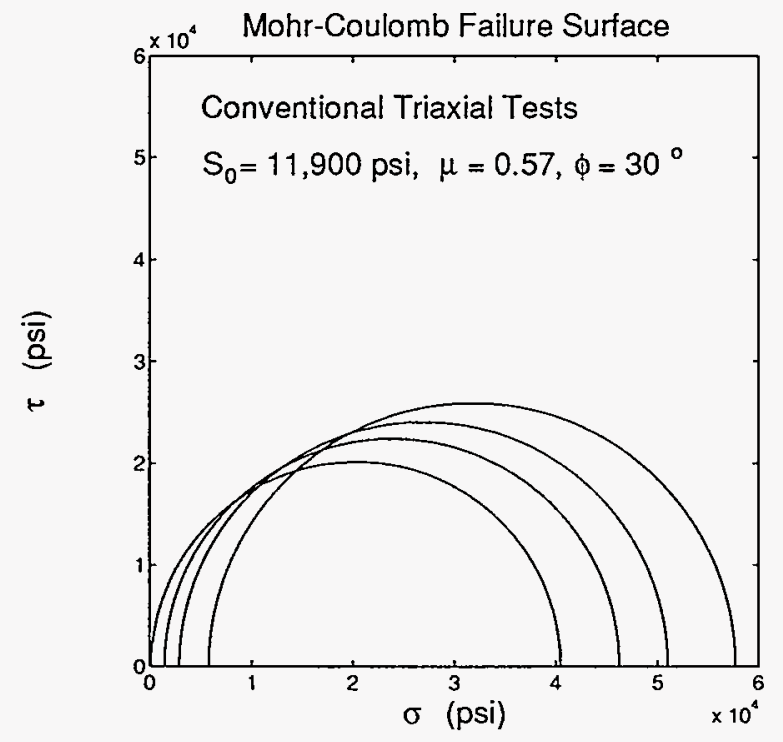

Figure 2: Mohr circle representation of the strength of Austin chalk for conventional triaxial stress

\section{Extension Tests}

Three extension tests were carried out at a minimum compressive stress of $1450 \mathrm{psi}$. Results are tabulated in Table 2. Two tests were done on core taken perpendicular to the bedding, resulting in the maximum compressive stress being parallel to the bedding, unlike all of the other tests. The third extension test was done on a core taken parallel to the bedding.

Strain data are plotted in Figure 4 as a function of the maximum compressive

Table 1: Conventional Triaxial Test Results

\begin{tabular}{rrrrr}
$P_{c}(p . s i)$ & $\sigma_{11, \text { mar. }}(p s i)$ & $\epsilon_{33, \text { ma. }}^{\prime} \times 10^{3}$ & $E^{\prime}\left(\times 10^{6} p . s i\right)$ & $\nu$ \\
\hline 145 & 40,500 & 0.53 & 9 & 0.31 \\
1450 & 46,300 & 1.12 & 8.7 & 0.29 \\
2900 & 51,600 & 1.98 & 8.5 & 0.28 \\
5800 & 57,700 & 3.14 & 9.5 & 0.31
\end{tabular}




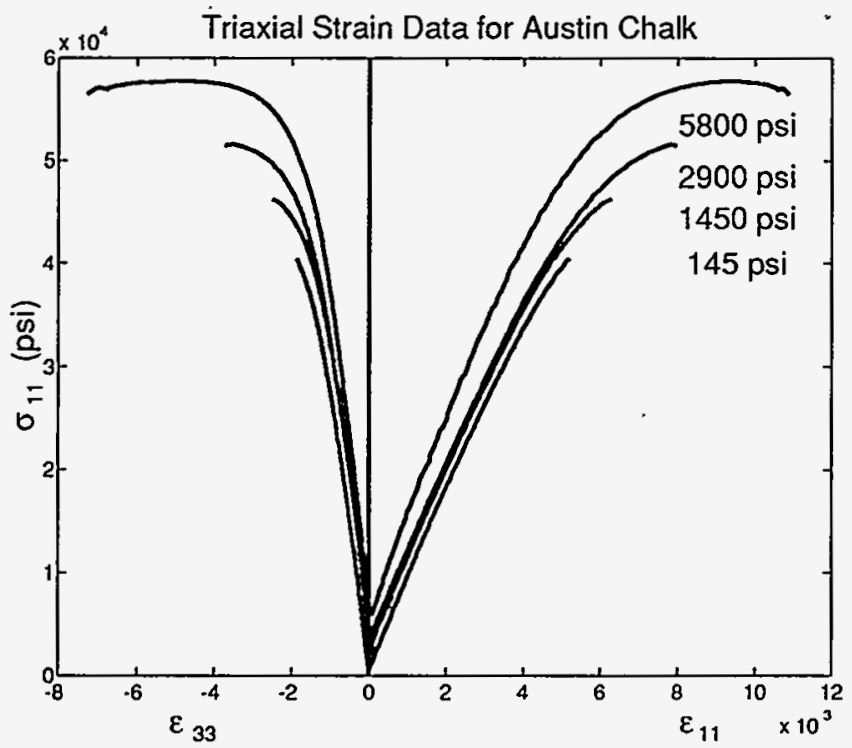

Figure 3: Strains as a function of confining pressure for conventional triaxial tests (compression is positive).

stress $\sigma_{11}=\sigma_{22}$. For all three tests, strain ( $\left.{ }_{(33}\right)$ in the direction of the minimum compressive stress was essentially a linear function of stress nearly to failure. Strain in the direction of the maximum compressive stress $\left(\epsilon_{11}\right)$ was linear for specimens cored perpendicular to bedding. However, for the specimen cored parallel to bedding there was a significant increase in stiffness as $\sigma_{11}$ surpassed $7000 \mathrm{psi}$. When compared to the specimens cored perpendicular to bedding, the sample was initially more compliant. The increase in stiffness is probably due to bedding-induced anisotropy.

As Table 2 shows, the strength of cores taken perpendicular to bedding was much lower than for the core taken parallel to bedding. As the failure mode for extensional loading is disking in the plane of loading, the tendency for pre-existing flaws to align with bedding would lower the strength of cores taken perpendicular to bedding and tested with maximum compressive stresses in the plane of bedding. In contrast, the core taken parallel to bedding was tested with the loading plane perpendicular to bedding, suppressing pre-existing flaws, and thus resulting in a higher strength. 


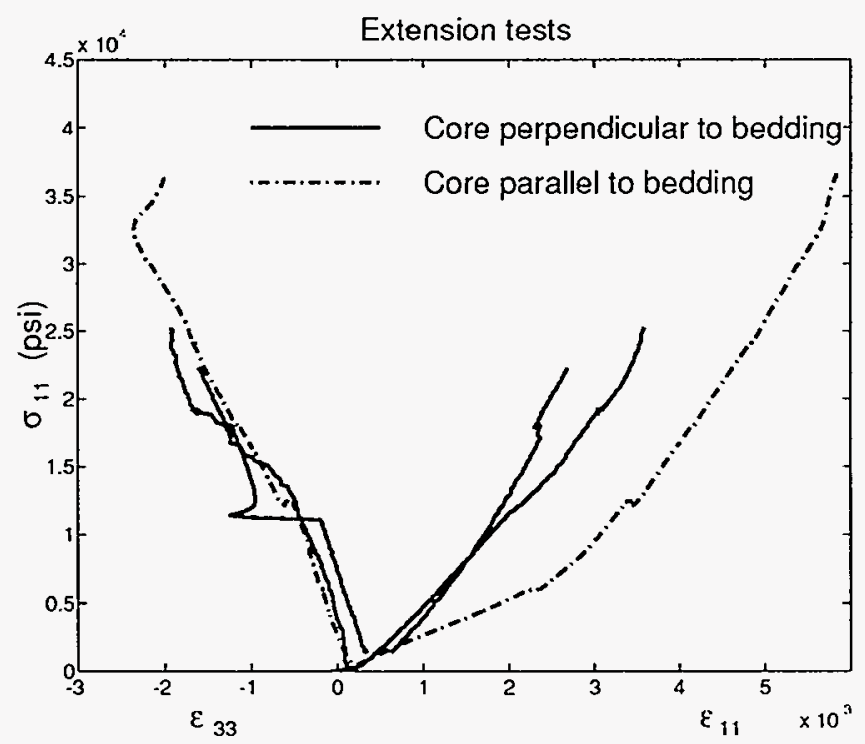

Figure 4: Strains for extension tests with the core axis parallel (dash-dot line) and perpendicular (solid lines) to the bedding plane.

\section{True Triaxial Tests}

Results from four true triaxial tests are tabulated in Table 3. Also included are results from one conventional triaxial test, $\left(\sigma_{11}>\sigma_{22}=\sigma_{33}=P_{c}=1450 \mathrm{psi}\right)$ and the three extension tests $\left(\sigma_{11}=\sigma_{22}>\sigma_{33}=1450 \mathrm{psi}\right)$. In all tests, $\sigma_{33}=1450$ psi.

Strain data for the maximum and minimum compressive stress directions are shown in Figure 5. The strain data have been arbitrarily offset to avoid confusion

Table 2: Results of the extension tests

\begin{tabular}{lrrr}
$\begin{array}{l}\text { Orientation of core } \\
\text { relative to bedding }\end{array}$ & $\sigma_{33}(p . s i)$ & $\sigma_{11, \text { max. }}(p . s i)$ & ${ }^{\prime}{ }_{33, m a r}$ \\
\hline Perpendicular & 1450 & 22,500 & $\approx 0$ \\
Perpendicular & 1450 & 25,200 & $\approx 0$ \\
Parallel & 1450 & 36,700 & $\approx 0$
\end{tabular}


due to overlapping. Results from the three extension tests are not included in Figure 5. See Figure 4 for the comparable plot of results from the extension tests.

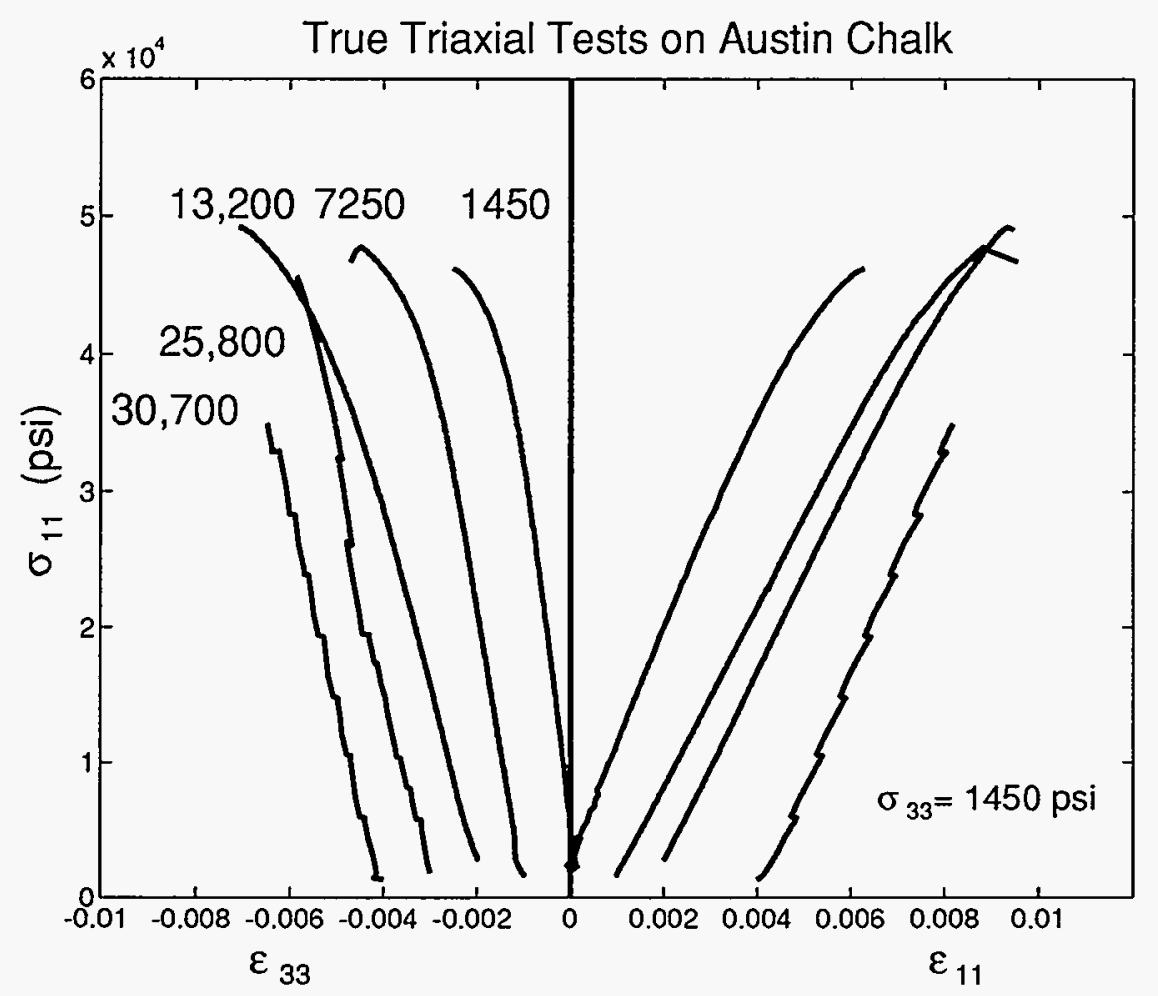

Figure 5: Strains in the maximum and minimum compressive stress direction $\left(\epsilon_{11}\right.$ and $\epsilon_{33}$ ) as a function of the maximum compressive stress for true triaxial tests. For all tests $\sigma_{33}=1450 \mathrm{psi}$. The numbers adjacent to the curves indicate the value of $\sigma_{22}$.

Figure 6 plots the failure surface in the $\sigma_{22}-\sigma_{11}$ plane at a constant minimum compressive stress of $1450 \mathrm{psi}$. Data points were reflected across the extensional loading line $\left(\sigma_{11}=\sigma_{22}\right)$ to complete the failure surface plot. One point in the tension quadrant (lower left) was obtained from a report by Martin et al. ([9], who used the Brazil test to determine the tensile strength.

The effects of the intermediate principal stress on strength are clear. At $\sigma_{22}=$ $13,200 \mathrm{psi}$, the failure strength is about $6 \%$ greater than would be expected from the conventional triaxial tests. For higher intermediate stresses, the strength decreases 
to a value below that determined in the conventional triaxial test $\left(\sigma_{33}=1450 \mathrm{psi}\right)$. Perhaps more important is the change in failure modes. At low $\sigma_{22}$, the failure was relatively ductile and uneventful. As the stress states approached the extensional mode, $\sigma_{11}=\sigma_{22}$, the failure became more brittle and violent.

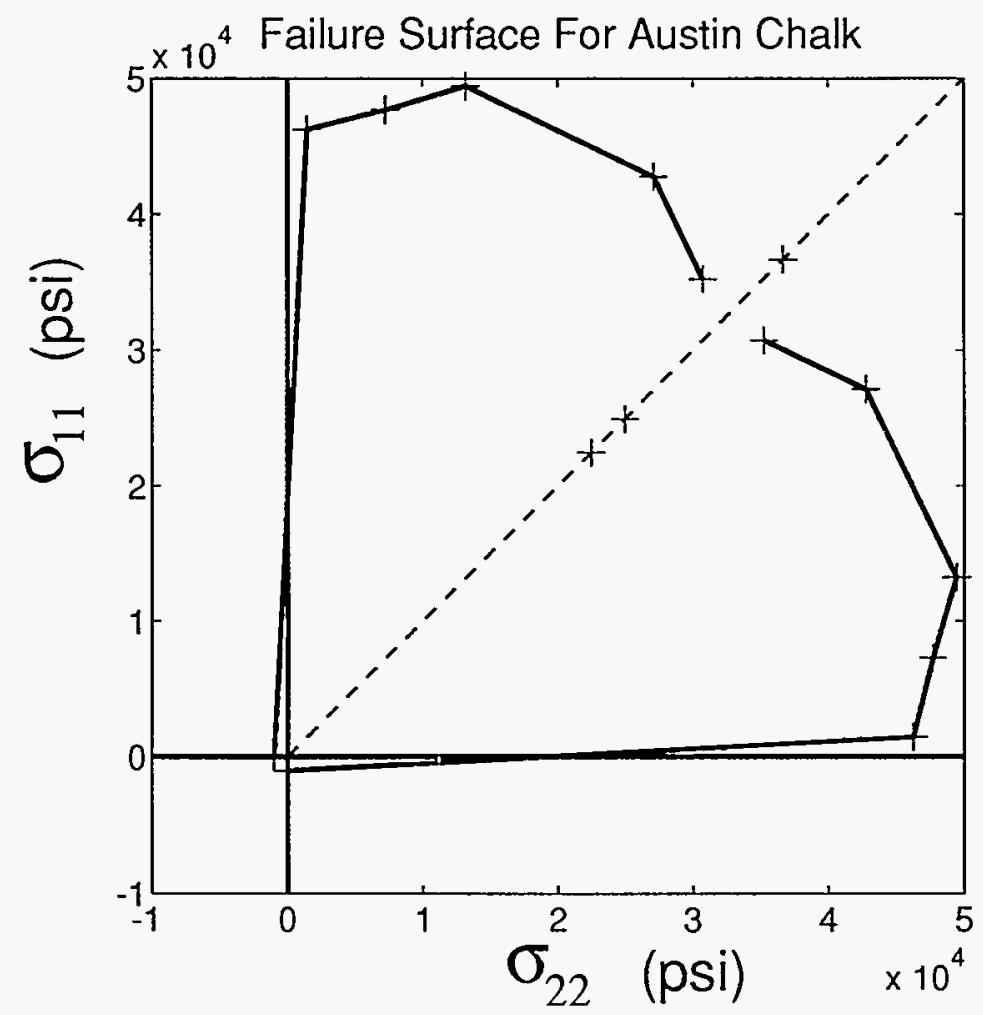

Figure 6: Failure surface for Austin chalk plotted in the $\left(\sigma_{22}-\sigma_{11}\right)$ plane. Extensional stress states lie on the dashed line.

A large effect of bedding on strength was observed. Two samples tested in the extensional mode (see Table 2 and Table 3), indicated by the crosses on the extensional loading line in Figure 6 at 22,500 and 25,200 psi, failed at a stress well below that predicted by a comparable true triaxial test done under nearlyextensional conditions. The nearly-extensional test was done in the true triaxial frame and failed at $\left(\sigma_{11}, \sigma_{22}, \sigma_{33}\right)=(35200,30700,1450)$ psi. The decrease in strength is due to the orientation of the stress state relative to the bedding plane. In the extension test, the maximum stresses were applied in the bedding plane. 
Table 3: Results for True Triaxial Tests

\begin{tabular}{rrrr}
$\sigma_{33}(p, s i)$ & $\sigma_{22}(p s i)$ & $\sigma_{11 . \max .}(p, s i)$ & $c_{33, \text { max }}^{\prime} \times 10^{3}$ \\
\hline$* 1450$ & 1450 & 46,300 & 1.1 \\
1450 & 7250 & 47,700 & 1.2 \\
1450 & 13,200 & 49,400 & 1.5 \\
1450 & 25,800 & 42,800 & $\approx 0$ \\
1450 & 30,700 & 35,200 & $\approx 0$ \\
$* 1450$ & 36,700 & 36,700 & $\approx 0$ \\
$* * 1450$ & 22,500 & 22,500 & $\approx 0$ \\
$* * 1450$ & 25,200 & 25,200 & $\approx 0$ \\
\hline
\end{tabular}

* conventional triaxial test

* extension test, core parallel to bedding

** extension test, core perpendicular to bedding

In the nearly-extensional test, the maximum stresses were applied in a plane perpendicular to the bedding plane.

The third extension test (see Tables 2 and 3) was done with the maximum stresses $\sigma_{11}=\sigma_{22}$ in the plane perpendicular to the bedding plane. As Figure 6 and Tables 2 and 3 show, the strength increased significantly to $36,700 \mathrm{psi}$, in line with the strength expected from the true triaxial tests.

\section{Conclusions}

In the vicinity of a borehole the three principal stresses are almost always unequal. This fact, plus the increased ability to control the orientation of horizontal boreholes relative to the in situ stress, were the motivations for examining the effects of the intermediate principal stress on deformation and failure of Austin Chalk. A failure surface has been constructed using the results from true triaxial tests and triaxial extension tests. The failure surface shows the effect of the intermediate principal stress on strength. Peak stress increases about $6 \%$ as the intermediate principal stress increases from 0 to $90 \mathrm{MPa}$. Further increasing the intermediate principal stress until the maximum and intermediate principal stresses are equal (extensional case) lowers the strength to below that of the chalk tested under 
uniaxial stress. Ductility, as measured by the non-linear component of the strain coaxial with the minimum compressive stress $\left(c_{33}^{\prime}\right)$, decreases as the intermediate principal stress increases. Because the intermediate principal stress influences the chalk strength and ductility, the stability calculations for boreholes may need to be reevaluated. As the Austin chalk is drilled at greater depths (current record is in excess of 15,000 feet. [Oil and Gas Journal Newsletter, Dec. 16, 1991]) the need for considering multiaxial stress effects will increase.

\section{References}

1. Corbett, K., M. Friedman and J. Spang, Fracture Development and Mechanical Stratigraphy of Austin Chalk, Texas. AAPG Bull.,71, pp. 17-28, 1987

2. Mogi, K., Effect of the intermediate principal stress on rock failure. J. Geophys. Res.,72, pp. 5117-5131, 1967

3. Brown, W.S., S. R. Swanson and W. R. Wawersik, Further Studies of Dynamic and Biaxial Loading of Rock.Defense Atomic Support Agency, Report DNA 28871,1972

4. Swenson, C. E., The Effect of the Intermediate Principal Stress on Deformation and Fracture of Rock. M.S. Thesis, Univ. of Utah, June 1972

5. Amadei, B., B. Janoo, M. Robison and R. Kuberan, Strength of Indiana Limestone in True Biaxial Loading Conditions. Proc. 25th Symp. Rock Mech., pp. 338-348. 1984

6. Ong, S. H. and Roegiers, J-C., Horizontal Wellbore Collapse in an Anisotropic Formation. Soc. Petr. Eng. Paper 25504, 1993

7. Ewy, R. T., Yield and Closure of Directional and Horizontal Wells. Proc. 34th U.S. Rock Mech. Symp., Madison, WI, 1993

8. Wawersik, W. R. and Carlson, L. W., in preparation, 1994

9. Martin, W., R. Devan, and J. Mclennan, Mechanical Properties of Austin Chalk, Terra Tek Report TR90-152. 1990 


\section{EXTERNAL DISTRIBUTION:}

5 U. S. Department of Energy

Attn: Reginal W. Spiller, FE-30 FORS

Sandra L. Waisley, FE-32 FORS

John Northington, FE-30 FORS

George Stosur, FE-33, GTN

Guido Dehoratiis, FE-30 FORS

Washington, DC 20585

$5 \quad$ U. S. Department of Energy .

Attn: Thomas C. Wesson, Director

Alex Crawley

Barbara Felber

Bob Lemmon

Rhonda Lindsey

P. O. Box 1398

Bartlesville, OK 74005

4 U. S. Department of Energy, METC

Attn: L. A. Graham

Royal Watts

K-H. Frohne

C. A. Komer

P. O. Box 880

Collins Ferry Road

Morgantown, WV 26505

3 Gas Research Institute

Attn: C. F. Brandenburg

F. K. Perry

S. Wohlhart

8600 Bryn Mawr Avenue

Chicago, IL 60631

6 Oryx Energy Company

Attn: Harold Illich

Howard White

Robert Skopec

Jim Aymx

Steve Chitwood

Ray B. Nelson

P. O. Box 2880

Dallas, TX 75221-2880 


\section{EXTERNAL DISTRIBUTION (con't.):}

1 Joe Perez

Senior Well Completion Engineer

Oryx Energy Company

Technology Center

P. O. Box 830936

Richardson, TX 75083-0936

2 Los Alamos National Laboratory

Attn: James N. Albright, Geoengineering Group, MSD443

Bob Hanold, MSD446

P. O. Box 1663

Los Alamos, NM 87545

2 Sonat Exploration

Attn: Mitch Cornette

Donald G. Russell, Chairman \& CEO

Four Greenway Plaza

P. O. Box 4792

Houston, TX 77210-4792

1 Richard C. Ellis

Pennzoil E\&P Company

P. O. Box 2967

Houston, TX 77252-2967

1 Arnis Judzis

BP Exploration

200 Westlake Park Blvd.

Houston, TX 77079

1 Howard McKinzie

Texaco

5901 S. Rice Avenue

Bellaire, TX 77401

1 Brian Tarr

Mobil Exploration \& Producing Service

P. O. Box 650232

Dallas, TX 77265-0232 


\section{EXTERNAL DISTRIBUTION (con't.):}

1 J. R. Bilhartz, Sr. JRB Oil and Gas Company 627 Mercury Avenue Duncanville, TX 75137-2235

1 David F. Boneau

Engineering Manager

Yates Petroleum Corporation 105 South 4th Street

Artesia, NM 88210

1 Larry G. Chorn Mobil Expl. \& Prod. Technical Center

P. O. Box 819047

Dallas, TX 75381-9047

1 Gerald R. Coulter Coulter Energy International 1910 Sparrows Point Ct.

Plano, TX 75023

2 Harvey E. Yates Company

Attn: A. J. Deans Steve Yates

P. O. Box 1933

Roswell, NM 88201

1 James E. Greve

Vice President, Engineering Bass Enterprises

201 Main Street, Suite 3100

Fort Worth, TX 76102

1 Robert Heming

Manager, Strategic Research

Chevron Petroleum Technology Corp.

2811 Hayes Road

Houston, TX 77082 
EXTERNAL DISTRIBUTION (con't.):

1 Edwin James

Crutcher-Tufts Prod. Co.

One Shell Square, Suite 3820

701 Poydras

New Orleans, LA 70139

1 Dave Kilpatrick

Santa Fe Energy Resources, Inc.

5201 Truxton Ave.

Bakersfield, CA 93309

1 Lee F. Krystinik

Union Pacific Resources Company

P. O. Box 7

Fort Worth, TX 76101-0007

1 Chet Love

Berry Petroleum Co.

27800 Hovey Hills Road

P. O. Bin X

Taft, CA 93268

1 Mark B. Murphy, President

Strata Production Company

P. O. Box 1030

Roswell, NM 88202-1030

1 J. Larry Nichols

Devon Energy Corp.

20 North Broadway

1500 Mid America Tower

Oklahoma City, OK 73102

1 William E. Preeg, Vice President

Schlumberger

8311 North RR 620

Austin, TX 78726

1 Chris M. Shaughnessy

Exxon Production Research Company

P. O. Box 2189

Houston, TX 77252-2189 
EXTERNAL DISTRIBUTION (con't.):

1 Bob Shore

Bakersfield Energy Resources, Inc.

2131 Mars Court

Bakersfield, CA 93308

1 Robert W. Siegfried

ARCO Oil and Gas Company

2300 West Plano Parkway

Plano, TX 75075

1 Irwin R. Supernaw

Texaco, Inc.

E\&P Technology Department

P. O. Box 425

Bellaire, TX .77402

1 Porter Underwood

Halliburton Energy Services

5500 Ming. Ave., Suite 365

Bakersfield, CA 93309

1 Rajendra N. Upadhyay

General Manager

Unocal Corporation

Energy Resources Division

P. O. Box 76

Brea, CA 92621

1 Ralph W. Veatch

Consultant

SEI

2651 E. 21st St., Suite 206

Tulsa, OK 74114

$1 \quad$ E. J. Voiland

Shell Western E\&P Inc.

5060 California Ave.

Bakersfield, CA 93309 


\section{EXTERNAL DISTRIBUTION (con't.):}

1 D. H. Gene Warley

President-Chairman

Midland Resources, Inc.

602 North Baird, Suite 200

Midland, TX 79701

1 Wendell Wiggins

Western Geophysical

3600 Briarpark

P. O. Box 2469

Houston, TX 77252

1 E. J. Witterholt

BP Exploration

P. O. Box 4587

Houston, TX 77210-4587 
INTERNAL DISTRIBUTION:

$\begin{array}{rll}1 & \text { MS0724 } & \text { D. L. Hartley, 6000 } \\ 1 & \text { MS0701 } & \text { R. W. Lynch, 6100 } \\ 1 & \text { MS0735 } & \text { D. E. Arvizu, 6200 } \\ 1 & \text { MS1033 } & \text { J. C. Dunn, 6111 } \\ 1 & \text { MS1033 } & \text { A. J. Mansure, 6111 } \\ 20 & \text { MS0706 } & \text { D. A. Northrop, 6112 } \\ 1 & \text { MS0706 } & \text { J. K. Linn, 6113 } \\ 1 & \text { MS0705 } & \text { M. W. Scott, 6114 } \\ 5 & \text { MS0705 } & \text { N. R. Warpinski, 6114 } \\ 1 & \text { MS1324 } & \text { P. B. Davies, 6115 } \\ 1 & \text { MS0750 } & \text { M. C. Walck, 6116 } \\ 1 & \text { MS0751 } & \text { S. R. Brown, 6117 } \\ 1 & \text { MS0751 } & \text { J. T. Fredrich, 6117 } \\ 12 & \text { MS0751 } & \text { D. J. Holcomb, 6117 } \\ 20 & \text { MS0751 } & \text { J. C. Lorenz, 6117 } \\ 1 & \text { MS0751 } & \text { W. A. Olsson, 6117 } \\ 10 & \text { MS0751 } & \text { L. W. Teufel, 6117 } \\ 1 & \text { MS0751 } & \text { W. R. Wawersik, 6117 } \\ 1 & \text { MS0751 } & \text { File, 6117 } \\ 1 & \text { MS0750 } & \text { H. R. Westrich, 6118 } \\ 1 & \text { MS1320 } & \text { E. J. Nowak, 6119 } \\ 1 & \text { MS1322 } & \text { J. R. Tillerson, 6121 } \\ 1 & \text { MS9018 } & \text { Central Technical Files, 8523-2 } \\ 5 & \text { MS0899 } & \text { Technical Library, 7141 } \\ 1 & \text { MS0619 } & \text { Technical Publications, 7151 } \\ 10 & \text { MS1119 } & \text { Document Processing, 7613-2 } \\ & & \text { For DOE/OSTI }\end{array}$

